\title{
LA SOCIEDAD CIVIL MIGRANTE: DIEZ TESIS PARA EL DEBATE
}

\author{
JONATHAN FOX* \\ WILLIAM GOIS**
}

\section{Resumen}

Este ensayo elabora diez propuestas sobre el carácter de la sociedad civil migrante y sus relaciones con estados y otros actores sociales y políticos. El concepto de la sociedad civil migrante se refiere a espacios públicos e organizaciones conducidos por migrantes.

Las propuestas tocan las diversas identidades colectivas, relaciones con sus sociedades de origen y de recepción, formas de organización, estrategias de incidencia, las dinámicas de sus coaliciones y el desfase persistente entre las agendas de migración y desarrollo. Estas propuestas se basan en lecciones aprendidas de diversas campañas de defensa de los derechos migrantes, incluyendo sus derechos humanos, laborales y los esfuerzos para desarrollar sus comunidades de origen. La discusión se basa principalmente en experiencias de organizaciones migrantes de América Latina y Asia.

Palabras clave: Sociedad civil migrante, derechos humanos, coaliciones, defensa migrantes, experiencias.

*Profesor de la University of California, Santa Cruz, Latin American and Latino Studies Department. Correo-e: jafox@ucsc.edu

**Coordinador Regional del Foro de Migrantes de Asia (MFA).Correo-e: mfa@pacific.net.hk Nota: Traducción del inglés de Mauricio Sánchez Álvarez. 


\section{Abstract}

This essay discusses ten propositions about the nature of migrant civil society and its relationships with states and other social and political actors. The concept of migrant civil society refers to migrant-led organizations and public spaces. The propositions address diverse collective identities, relationships with societies of origin and settlement, forms of organization, advocacy strategies, dynamics of coalition politics and the persistent disconnect between migration and development agendas. The propositions are based on lessons learned from diverse campaigns in defense of immigrant rights, including their human rights, labor rights and their efforts to develop their communities of origin. The discussion draws principally from experiences of organizations of migrants from Latin America and Asia.

Keywords: Migrant civil society, human rights, coalitions, migrant defense, experiences. 

a acción colectiva de los migrantes adopta muchas formas, que a menudo se basan en sus comunidades transnacionales y en iniciativas con relación a sus derechos laborales. Estos fundamentos sociales constituyen la base de la «sociedad civil migrante», que surge en espacios públicos que se extienden más allá de las fronteras nacionales.

¿Cuáles son algunas de las implicaciones de conjuntar estas tres palabras: 'sociedad civil migrante'? Puesto en términos sencillos, la sociedad civil migrante se refiere a organizaciones de base y a instituciones públicas dirigidas por migrantes. Más específicamente, ello incluye cuatro ámbitos muy tangibles de acción colectiva, cada una de las cuales está constituida por actores, mientras que cada conjunto de actores también constituye una arena. Estas cuatro ámbitos incluyen: organizaciones de base compuestas y dirigidas por migrantes, espacios públicos autónomos (tales como reuniones culturales o políticas a gran escala), organizaciones civiles conducidas por migrantes, así como medios de comunicación dirigidos por migrantes. ${ }^{1}$

La razón fundamental para centrarse en la dimensión migrante de la sociedad civil estriba en querer alentar a los actores migrantes, a los observadores y a los aliados potenciales, a reconocer a las organizaciones mediante las que los migrantes han construido su capacidad de auto-representación, como una base para construir coaliciones de manera más equilibrada.

Ciertamente, las sociedades civiles migrantes a menudo surgen del diálogo con una sociedad civil más amplia, situación que varía mucho, según si esas relaciones son locales (o nacionales), a distancia, o ambas. Es decir, las organizaciones migrantes tienden a emerger ya sea como parte del compromiso cívico que adquiere gente recién llegada con su sociedad de residencia, o en relación con la sociedad de su país de origen. En otras palabras, esta esfera pública puede referirse tanto al ala (e)migrante de la sociedad emisora, como a las comunidades (in)migrantes en la sociedad receptora. Estas distin-

\footnotetext{
${ }_{1}$ Nótese que esta definición se inscribe en una larga tradición que ha definido a la sociedad civil en contraste con el Estado y el mercado, por lo que no incluye a gran parte de los actores del sector privado (con la notable excepción de los medios masivos de comunicación que se orientan hacia migrantes como público principal, y que sí existen). Para una discusión más amplia sobre la noción de sociedad civil migrante, véase Fox $(2006,2007)$ así como Fox y Bada (2008).
} 
tas arenas a veces se superponen, de modo que una interrogante clave tiene que ver con dónde, cuándo y en qué condiciones los migrantes se comprometen en los ámbitos tanto local como transnacional. A su vez, estas formas de membresía activa transfronterizas y articuladas en múltiples niveles representan una dimensión de un proceso más amplio de la formación de la sociedad civil transnacional.

Es claro que esta categoría muy amplia de acción colectiva incluye a muchos tipos distintos de migrantes. Para empezar, es muy notoria la diferencia fundamental entre los trabajadores migrantes temporales y las comunidades de trabajadores inmigrantes, dado que los trabajadores contratados a corto plazo tienen mucho menos oportunidades para construir instituciones propias estando fuera del país. Asimismo, los propios migrantes varían considerablemente entre sí, en términos de su interés en y de su capacidad para comprometerse permanentemente con su lugar de origen. A su vez, los Estados y las sociedades de origen difieren en términos de su postura hacia sus ciudadanos en el exterior. ¿̇En qué momento considera una sociedad nacional que la emigración es un asunto social, cívico o político? En tanto, dentro de las comunidades establecidas de trabajadores inmigrantes, también su estatus legal y el ambiente político claramente influyen directamente en su capacidad para la acción colectiva.

Para los individuos y las familias migrantes, a menudo uno de los dilemas fundamentales es cómo superar el sentimiento de no ser «ni de aquí ni de allá». De manera similar, para las sociedades civiles migrantes, el desafío consiste en cómo superar la exclusión que se puede generar tanto en la sociedad emisora como en la receptora, a fin de obtener reconocimiento e inclusión "tanto aquí como allá».2

El concepto de sociedad civil migrante es el punto de partida de las siguientes diez propuestas para la discusión, y en la configuración de cada una resulta de se combinan: trabajo de investigación, experiencia en la construcción de coaliciones y el ejercicio de defensoría. Estas propuestas abordan una serie de cuestiones analíticas relacionadas entre sí, y que tienen que ver con las organizaciones migrantes, las luchas por los derechos y las campañas a

2 En periodos históricos anteriores, los migrantes han enfrentado muchos asuntos similares. Para una revisión exhaustiva de la literatura histórica al respecto, véase Moya (2005). 
favor de estrategias de desarrollo que brinden alternativas a la pobreza y la migración.

\section{Las organizaciones que constituyen la sociedad civil migrante se basan en múltiples identidades colectivas, a menudo superpuestas}

$\mathrm{Al}$ igual que la acción colectiva en general, las organizaciones migrantes surgen de cierta combinación de intereses e identidades compartidas. Algunos grupos se constituyen principalmente a partir de un origen común, ya sea que provengan de una misma comunidad o del mismo país, posiblemente alentados por actores gubernamentales, civiles o políticos situados en su país de origen. Sin embargo, en lo que a organización se refiere, las identidades migrantes compartidas constituyen una espada de dos filos, pues aunque pueden facilitar algunas estrategias organizativas, también pueden impedir otras.

En cambio, algunas agrupaciones migrantes que abogan por sus derechos como tales reúnen a gente que proviene de diferentes países, más particularmente para centrarse en agendas comunes con respecto a derechos laborales de cara a los empleadores, o para la cuestión de su estatus legal de cara a los gobiernos. En las sociedades receptoras, como retos centrales, los derechos humanos y el estatus legal pueden crear intereses comunes entre migrantes, quienes de otro modo pueden diferir considerablemente en términos de nacionalidad, etnicidad, lengua, clase, casta o ideología. No obstante, y a pesar de los «intereses comunes objetivos», generalmente se requiere de estrategias políticas conscientes para conjuntar a trabajadores migrantes de distintos orígenes nacionales, como en los casos del proceso organizativo de trabajadoras domésticas en Hong Kong, lideradas por filipinas politizadas, o de las iniciativas emprendidas por trabajadores latinos inmigrantes en los Estados Unidos, a menudo encabezadas por inmigrantes que se habían politizado en su país de origen. ${ }^{3}$

3 Sobre la organización entre los trabajadores latinos inmigrantes en los EUA, véase Bacon (2008), Fine (2006) y Milkman (2006), entre otros. Sobre la organización de trabajadores 
Entre las organizaciones de migrantes que actúan en torno a sus derechos, ciertamente hay diferentes tipos. Unos grupos se centran principalmente en cuestiones de su país de origen, mientras que otros se ocupan, más bien, de la situación de los migrantes en su país de residencia. Sin embargo, con el tiempo esta diferencia se ha ido diluyendo, a medida que un número cada vez mayor de organizaciones de migrantes persigue una agenda que es tanto «de aquí como de allá». En el proceso, los migrantes también se han ido organizando simultáneamente a través de múltiples canales, ya sea que se congreguen como trabajadores en su lugar de trabajo, o como mujeres, o miembros de determinado grupo étnico, sobre todo cuando su papel en el mercado de trabajo o en su comunidad está determinado por el género o la raza. Al mismo tiempo, también pueden organizarse como oriundos de un mismo pueblo, cuando se busca apoyar el desarrollo comunitario de éste; y cuando se dirigen al gobierno de su país de origen para que éste atienda sus preocupaciones, pueden organizarse como ciudadanos connacionales, o como simpatizantes de un partido político de cobertura nacional. Sin embargo, aunque los migrantes con frecuencia pueden perseguir distintas agendas en forma simultánea, por medio de organizaciones diferentes, puede que sus 'aliados potenciales' no alcancen a visibilizar el repertorio completo de sus acciones. $^{4}$

\section{En la constitución de las formas de organización social} de los migrantes intervienen, de un lado, estos mismos y del otro, su entorno político institucional, así como la disponibilidad de aliados no migrantes en el país huésped

De nueva cuenta, al igual que la acción colectiva en general, los migrantes no se organizan en el vacío. Su capacidad para hallar los espacios libres reque-

migrantes en Hong Kong, véase Kessler (2009), Rother (2009) y Solomon (2009). Sobre la organización de trabajadoras domésticas filipinas en Europa, véase Anderson (2001, 2010) y Briones (2009)

${ }_{4}$ Para un análisis etnográfico de las múltiples identidades que se dan simultáneamente entre migrantes, véase Stephen (2007) entre otros. 
ridos para conjuntarse en la búsqueda de metas comunes depende mucho del respectivo ambiente social, cívico, político y espacial. La libertad de movimiento y de asociación son fundamentales, pero ese espacio varía ampliamente entre países, lugares de trabajo y comunidades, y depende con mucho del estatus migratorio. De forma similar, el acceso a los distintos tipos de información que se requieren para organizarse (incluyendo el lenguaje común) también es altamente desigual; sin embargo, es crucial para identificar aliados potenciales y para evaluar posibles oportunidades de cambio.

Si bien algunos gobiernos representan casos extremos, ya sea de control autoritario o de libertad democrática, muchos no encajan claramente en esa dicotomía. Por ejemplo, algunos gobiernos pueden imponer limitaciones a los derechos políticos (como Hong Kong) o negar el estatus legal a un gran número de trabajadores migrantes (como los EUA), a la vez que respetan algunos derechos civiles o sociales básicos que, por otra parte, son muy significativos para los migrantes. Habitualmente, se requiere cierto grado de libertad de asociación como una condición previa fundamental para defender otros derechos mediante la acción colectiva. ${ }^{5}$ Es crucial la existencia de espacios seguros para poder reunirse, como en los casos de las iglesias para los filipinos en el extranjero, o de las mezquitas en Hong Kong para los trabajadores indonesios. Por otra parte, también puede haber una marcada desconexión entre los derechos civiles de los migrantes, en tanto principio legal, y el grado en que éstos se pueden ejercer en la práctica, como es el caso de los migrantes centroamericanos en México, cuyos derechos se violan impunemente.

El campo de los derechos sociales para los migrantes también puede ser muy desigual y variar tanto de un país a otro, como entre distintos puntos del tema. Piénsese en la desconexión, por lo demás contradictoria, entre los dere-

${ }_{5}^{5}$ Contrástese por ejemplo, el grado de libertad de asociación que hay en Hong Kong con el de Singapur. Una mayor apertura en Hong Kong permitió que la ciudad se convirtiera en el lugar pionero para el activismo político de los migrantes Filipinos, quienes siguen estando entre los más activos de Asia. Considérense también las emergentes protestas de los trabajadores birmanos migrantes en Thailandia, que aunque son aisladas y duramente contestadas bajo un régimen apenas semi-democrático, dan mayor margen de maniobra a la organización de los trabajadores que el existente en su país natal (Pangspa 2009). 
chos civiles y los derechos sociales en los EUA, donde los trabajadores indocumentados pueden ser expulsados sumariamente en cualquier momento, $y$ a menudo sin el proceso debido; sin embargo, sus hijos tienen el derecho (por mandato constitucional, todavía) de asistir a la escuela pública y el derecho legal (al menos en el papel) de ser atendidos en las salas de emergencia de los hospitales en su propia lengua; y sus empleadores supuestamente deben respetar el salario mínimo federal, así como las leyes de seguridad en el trabajo. ${ }^{6}$

El ambiente del país receptor también incide en la disponibilidad de aliados potenciales entre fuerzas sociales y políticas locales y nacionales, que estén a favor de los derechos de los migrantes, como ha sido el caso de instituciones religiosas, sindicatos, grupos de defensa legal y partidos políticos. No obstante, en un país receptor varían muchísimo tanto la densidad como la disposición de los aliados potenciales, tanto en términos de geografía como de lengua, religión, asunto específico e ideología. Por ejemplo, es más probable que los migrantes que comparten idioma, religión o ideología con fuerzas significativas dentro la sociedad civil del país receptor, tengan más posibilidades de construir lazos sociales sólidos que trasciendan las diferencias entre nacionalidades (compárense los lazos entre latinoamericanos y latinos de EUA con la situación de los inmigrantes musulmanes en Europa).

El entorno político e institucional que configura las posibilidades para la acción migrante también incluye el papel que desempeñan los gobiernos del país emisor y del país de tránsito. Por ejemplo, frente a la impunidad persistente de quienes violan los derechos de los transmigrantes en México, existe poca evidencia de que, por ejemplo, los centroamericanos en México se sienten suficientemente seguros como para «salir a la luz» pública y protestar por la forma en que los tratan. Pero por otra parte, el gobierno mexicano sí ha actuado de maneras importantes en respuesta a las exigencias de sus nacionales en los EUA, en el sentido de adoptar un papel activo en su defensa, el cual incluyen numerosas medidas para defender a los indocumentados. Una de las respuestas oficiales mexicanas más notables consistió en emitir millones de matrículas consulares en la década pasada. ${ }^{7}$ El gobierno de Méxi-

6 Véase, por ejemplo, Gleeson (2010).

7 No se tiene claro el número total de mexicanos que cuentan con identificaciones consulares, ya que la información pública oficial reporta únicamente cuántas se extienden al año, sin 
co y las organizaciones de defensoría de los inmigrantes han convencido a muchas dependencias gubernamentales estadounidenses (incluyendo la policía), así como a instituciones financieras, de aceptar este documento como una identificación oficial. De otra manera, muchos mexicanos serían «doblemente indocumentados» al carecer de reconocimiento oficial tanto de parte los EUA como de su propio país.

Una forma de resumir esta propuesta es señalando que «el contexto importa». En otras palabras, para el proceso organizativo, el ambiente local suele variar mucho dentro de ambos países: el de origen y el de destino. El contexto varía en al menos dos modos importantes. Primero, el poder de los opositores a los derechos de los migrantes se distribuye en forma desigual. Segundo, el poder de los aliados potenciales de los migrantes está distribuido desigualmente dentro de cada país. En los EUA, por ejemplo, las posibilidades de formar coaliciones sólidas e influyentes varían considerablemente porque las instituciones estadounidenses «amigables hacia el inmigrante» son mucho más fuertes en unas ciudades que en otras. En particular, la presencia de actores que apoyan a los migrantes, como iglesias, uniones sindicales y medios radiofónicos y televisivos en español es muy desigual a lo largo y ancho del país. La infraestructura fundamental para la movilización a favor de los derechos de los inmigrantes en los EUA, está depositada no tanto en organizaciones nacionales como en coaliciones multisectoriales urbanas, que vinculan a las organizaciones dirigidas por migrantes con las estadounidenses. Más importante aún, la envergadura y la densidad de los socios más consistentes de coaliciones de inmigrantes, las instituciones de la sociedad

desglosar las que corresponden a reposiciones o cambios de domicilio. De todos modos es una gran cantidad, ya que según el Informe de Gobierno de 2010, los consulados mexicanos han extendido 9.4 millones de identificaciones desde el año 2000. Para una discusión más amplia sobre los aspectos políticos de estas identificaciones, véase Varsanyi (2007). La red consular de El Salvador pone a disposición de sus ciudadanos en los Estados Unidos un servicio aún más peculiar, citándolos a reuniones donde les ofrecen asistencia técnica directa y personalizada para guiarlos a través de los procedimientos migratorios (requeridos por el gobierno de los Estados Unidos), incluyendo los correspondientes a una categoría especial llamada «estatus de protección temporal» que se creó en los años noventa como respuesta a campañas previas que habían encabezado migrantes centroamericanos, con respecto a la regularización que sobrevino tras los desplazamientos provocados por la guerra. (Prof. Cecilia Rivas, de la Universidad de California, Santa Cruz, comunicación personal, octubre de 2010). 
civil latina estadounidense, varían mucho de ciudad a ciudad y de un estado a otro, al igual que la capacidad de representación política de los ciudadanos latino estadounidenses.

Este terreno desigual para el reconocimiento de las voces de los migrantes es especialmente relevante, porque si bien los migrantes han demostrado claramente su capacidad para construir sus propias instituciones sociales y cívicas, su potencial para dar el paso siguiente, creando una voz y un poder políticos en el proceso de formulación de políticas, requiere la construcción de coaliciones con las instituciones establecidas. A su vez, la creación de este espacio compartido en los niveles de ciudad/pueblo o de estado/provincia, puede reconfigurar el ambiente dentro del cual los migrantes deciden cuándo y cómo comprometerse en materia de defensoría y de acción colectiva. Este tipo de "círculo virtuoso» representa una vía potencial significativa para el empoderamiento de los migrantes, la cual sólo se podrá descubrir y comprender -ser cuando se desenvuelvan los patrones de compromiso cívico en el nivel local.

\section{Las agendas basadas en los derechos dependen del marco} de los derechos humanos de las Naciones Unidas, el cual se ha construido con el consenso de la comunidad internacional

Aunque mucho del discurso internacional sobre los derechos de los migrantes se ha construido en el marco de la Declaración Universal de los Derechos Humanos de 1948, muchos migrantes habrán tenido poco o ningún acceso de esos derechos previo a su experiencia migratoria. Las agendas basadas en derechos surgen de un profundo sentido personal de justicia y de derecho en los propios individuos. En muchos países de origen, sobre todo en aquellos en que el Estado tiene como política y propósito deliberados el desplegar trabajadores migrantes, a fin de incrementar las remesas que llenen sus arcas, algunos programas de orientación para el migrante próximo a partir, sí contienen información relevante para sus derechos como trabajador migrante. Sin embargo, algunos gobiernos también socavan este discurso oficial sobre derechos haciendo un énfasis adicional en las responsabilidades, 
para contrarrestar la posibilidad de que sus emigrantes se vuelvan «demasiado empoderados» y que, por lo mismo, no estén dispuestos «a tolerar una ligero infracción» a sus derechos en un «contexto extranjero». Por ejemplo, funcionarios del gobierno filipino han expresado en ocasiones su enojo con migrantes que acuden a la embajada o que huyen de sus empleadores a la más mínima infracción a sus derechos. Además, los funcionarios gubernamentales de Bangladesh, cuando discutían la ratificación de la Convención de Trabajadores Migrantes, expresaron su preocupación porque la ratificación podía dar lugar a que sus connacionales perdieran oportunidades en el mercado de trabajo. También se ha dicho que los migrantes deberían ser capaces de tolerar cierta violación de sus derechos, ya que de por sí tampoco gozan de ellos en sus países de origen.

Poca consideración se le da al hecho de que el marco de referencia internacional sobre los derechos humanos está directamente vinculada al principio de la no discriminación. Como personas, los migrantes tienen noción de su propia dignidad y el respeto que merece, y que, cuando éstos se violan, sienten que se ha cometido una injusticia en su contra. Cuando experiencias comunes de abuso y violación a los derechos, así como el trato indigno se ocurren de manera articulada, también encuentran apoyo en una comunidad más amplia. Sin embargo, la búsqueda por parte de los migrantes de arreglos justos para los agravios que sufren está determinado en gran parte por la disponibilidad de apoyo y mecanismos de desagravio en la sociedad. Si bien puede que los trabajadores migrantes no estén en capacidad de definir legalmente su sentido de derecho, como reclamar su derecho a un pago equitativo, sí perciben que se violan sus nociones de auto respeto y de auto dignidad cuando sienten que hay una gran desproporción entre lo que se les da y lo que les corresponde por derecho.

Este discurso de los derechos humanos tiende un puente entre los derechos morales (o «naturales») y los derechos legales. El reto del contexto consiste, en gran medida, en asegurar los derechos humanos y legales de todos los migrantes independientemente de su estatus. En muchos países receptores, las comunidades que abogan por los derechos humanos y laborales están dispuestas a encargarse de la causa de los migrantes documentados. Pero al mismo tiempo, suelen bregar mucho para encontrar vías adecuadas 
para apoyar a migrantes en situaciones irregulares, lo cual se agrava cuando a los migrantes se les culpa de tener un estatus indocumentado.

La interacción entre estas nociones de derechos inherentes, de dignidad y de contexto, puede observarse, por ejemplo, cuando las trabajadoras domésticas exigen gozar de un día libre, un reclamo que ahora está siendo respaldado por una campaña global. Mientras tanto, la ort continúa deliberando sobre la necesidad de una Convención Internacional sobre el reconocimiento del trabajo doméstico como lo que es: trabajo. Otro ejemplo de un derecho que reclaman los trabajadores migrantes es su llamado a poner fin a que sus empleadores retengan 'oficialmente' sus documentos personales y de viaje, lo cual no sólo los inmoviliza, sino que incrementa su vulnerabilidad al abuso y a la explotación. Esta situación se agrava aún más cuando el estatus legal del migrante está atada al empleador, de tal modo que si intenta escapar a esta situación automáticamente habría un cambio de estatus, de legal a indocumentado, y en consecuencia, estaría sujeto a arresto, detención y deportación. El comprender que intrínsicamente se está cometiendo una injusticia ha llevado a la ort y a los defensores de los derechos humanos a denunciar esta práctica como una forma contemporánea de esclavitud.

Aunque la agenda acerca de los derechos se funda en un sentir de que, efectivamente, se están cometiendo injusticias, para que ésta cobre vigencia y actualidad, es necesario que exista un sistema de apoyo, u oportunidades para expresar agravios, protestas o reclamos en pos de una reparación. A su vez, este contexto implica el imperio de la ley, por el cual las leyes del país y su práctica acogen debidamente al encuadre internacional del discurso de los derechos humanos. Pero, żcómo pueden llegar expresarse reclamaciones en contextos en que no impera la ley? Las recientes protestas laborales de trabajadores migrantes en Oriente Medio son un buen ejemplo de seres humanos que poseen un sentido inherente de justicia y dignidad, Por ejemplo, cuando 2000 trabajadores originarios de Bangladesh tomaron las calles en Kuwait, convencieron a un periódico bengalí de circulación nacional quehiciera un llamado al gobierno para que defendiera sus derechos como connacionales. $^{8}$

8 Según el periódico Daily Star (2008): «Más de 500 trabajadores de limpieza se movilizaron en manifestaciones callejeras hasta que la policía los dispersó al anochecer, con gases lacri- 
A pesar de la existencia de un entorno en el que no se toleran los disturbios laborales y en que los mecanismos para enmendar agravios todavía no están plenamente establecidos ni son operativos, complicado además por la escasa presencia de organizaciones de derechos humanos o de grupos locales de apoyo, los trabajadores migrantes de Asia del Sur)encontraron el valor para actuar colectivamente, armando una protesta callejera a fin de exigir que se reconocieran sus derechos y poner fin a una injusticia sufrida en carne propia: el no pago de sus salarios. En Corea del Sur, los inmigrantes indocumentados han llegado a formar su propio sindicato, con el respaldo de la Confederación Coreana de Sindicatos de Libre Comercio (Korean Confederation of Free Trade Unions, KCFTU). Ellos han persistido a pesar de que su liderazgo ha sido sistemáticamente blanco de arrestos, detenciones y deportaciones. En la actualidad está pendiente una decisión de la Corte Suprema del país sobre los derechos de los migrantes indocumentados en Corea del Sur, que está por definir la obligación moral y legal del Estado de reconocer e instrumentar el derecho de todos los trabajadores a la libertad de asociación (Convenio 87 de la orT), así como a la negociación colectiva (Convenio 98 de la OIT), codificados por la oIT como convenios fundamentales y como Normas y Principios y Derechos Fundamentales en el Trabajo.

El marco de referencia de las Naciones Unidas, al cual se acogen virtualmente todos los países del mundo, proporciona el discurso sobre los derechos humanos que legítimamente puede reclamar un carácter universal.

mógenos y macanas, arrestando a varios trabajadores... Al criticar la falta de control que el gobierno tiene sobre las compañías de limpieza, varios miembros del parlamento kuwaití señalaron que, en vez de buscar soluciones para poner fin a las protestas, el gobierno ha empezado a considerar la posibilidad de contratar mano de obra proveniente de otros países asiáticos, excepto Bangladesh o Pakistán, ya que se sabe que los trabajadores de estos países tienden a recurrir a la violencia en situaciones similares. El parlamentario Saleh Ashoor señaló al gobierno como el único responsable de la violencia desatada ante la reciente desosiego de los trabajadores. Expresó que el gobierno es el encargado de cumplir los contratos y la asignación puestos de trabajo a las compañías, por lo que debió haberlas controlado, supervisando efectivamente su funcionamiento. Ashoor dijo que las demandas expresadas por los trabajadores que protestaban, estaban en completa consonancia con la ley y dentro del marco de los derechos humanos fundamentales. También criticó la práctica inhumana de los empleadores al retener las tarjetas bancarias de sus empleados y pagarles muy por debajo del salario por el que fueron contratados» 
Mediante el consenso de la comunidad internacional, el enfoque basado en los derechos tiene la capacidad para darle sustancia a la exigencia de derechos humanos universales que trascienden las fronteras.

La fuente fundacional de los derechos humanos se origina en la madre de todos los documentos relativos a los derechos humanos: la Declaración Universal de los Derechos Humanos (UDHR, por sus siglas en inglés), quel fue aprobada por la Asamblea General de las Naciones Unidas en 1948. Sus disposiciones se basan en los principios de igualdad, no discriminación e indivisibilidad. Según la Declaración, todas las personas poseen derechos humanos "sin distinción alguna de raza, color, sexo, idioma, religión, opinión política o de cualquier otra índole, origen nacional o social, posición económica, nacimiento o cualquier otra condición» (Artículo 2). Ahora bien, los derechos humanos relativos a los trabajadores migrantes se pueden encontrar en varios convenios vinculantes de la onU. Así, el Pacto Internacional sobre Derechos Económicos, Sociales y Culturales (ICESCR, por sus siglas en inglés) establece el derecho a trabajar, que se define como «la oportunidad de ganarse la vida mediante un trabajo libremente escogido o aceptado» 1 (Artículo 6). El trabajo al que se refiere el Artículo 6 debe ser un trabajo digno (Artículo 7). El Pacto Internacional de Derechos Civiles y Políticos (ICCPR, por sus siglas en inglés) establece que nadie será retenido en esclavitud o por servidumbre u obligado a desempeñar trabajos forzados u obligatorios (Artículo 8).

La Convención sobre la protección de los derechos de todos los trabajadores migratorios y de sus familiares (ICRMW)entró en vigor en julio de 2003. No propone derechos nuevos para los trabajadores migrantes, sino que más bien busca particularizar y destacar lo distintiva que es la vulnerabilidad que enfrentan, debido a que no son ciudadanos del país en el que están empleados.

Todos los instrumentos de la onU y de otras iniciativas que tienen pretensiones universales, en realidad apelan a nociones de indivisiblilidad e inalienabildad del individuo. Si bien las agendas basadas en derechos pretenden la universalidad, ésta no se alcanza mediante la ley positiva; más bien, tiene fundarse intrínsecamente en una noción de justicia de y para el individuo.

Por último, la escala actual de la movilidad laboral en el mundo y la migración transfronteriza están atrayendo cada vez más la atención de los 
medios de información. Por ejemplo, los continuos informes que éstos han difundido sobre abusos y explotación de trabajadoras domésticas indonesas en Malasia y el activo cabildeo de la sociedad civil migrante en Indonesia y Malasia, han dado como resultado un acuerdo bilateral entre ambos países. Sin embargo, aunque a ese acuerdo todavía se le puede sacar más provecho, la sociedad civil migrante continúa actuando para asegurar que la protección de los derechos de los trabajadores migrantes mantenga un lugar importante en la agenda de los gobiernos. ${ }^{9}$

Queriéndolo o no, esto ha hecho ha vuelto mucho más visibles, las condiciones de los migrantes y la socialización de sus derechos humanos y laborales, lo cual les ha permitido empoderarse, hablando de su situación y exigiendo cambios mediante la participación en procesos y discursos, por los cuales se formulan políticas que determinan el curso de sus vidas, ya sea en el paíse de origen o en el de destino. La atención mediática se ha ampliado y también ha desafiado a la comunidad que actúa en el ámbito de los derechos humanos a «operativizar» el marco de referencia internacional de dicha temática. Ello, a fin de hacer tangible el principio básico de que el Estado, es responsable de proteger los derechos humanos de sus ciudadanos aún más allá sus fronteras, así como de los derechos de todo individuo, independientemente de su nacionalidad, que se encuentre dentro de su jurisdicción territorial.

4. Para equilibrar las diferencias entre, por un lado, la labor de servicio $y$ de defensoría y por el otro, la labor dedicada a la formulación de políticas de defensoría, que es más estratégica, hay que realizar intercambios continuos y divisar estrategias deliberadas

Para apoyar a los trabajadores migrantes, hay que trabajar de muchas formas distintas y en varios niveles. De entrada, los migrantes enfrentan penurias y traumas que los afectan cotidianamente. En consecuencia, es importante y necesario disponer de organizaciones que puedan responder, sirviéndo-

9 Véase http://www.tempointeractive.com/hg/nasional/2010/09/22/brk,20100922279715, uk.html. 
les directamente, ya sea visitándolos en centros de detención, preparándolos para su repatriación, asesorándolos, o proporcionándoles amparo cuando están angustiados. La lista de asuntos es enorme. Por otro lado, esta labor orientada a dar servicio resultaría interminable si la raíz de estos problemas no se enmarcara en políticas enfocadas a la defensoría. Sin una estrategia deliberada que pueda iniciar un cambio en las políticas, a fin de que éstas puedan proteger los derechos de los migrantes en cada etapa del proceso migratorio, las incidencias de explotación no tendrán fin.

El Marco multilateral de la Organización Internacional del Trabajo (OIT) para las migraciones laborales, que no es vinculante, provee un entorno para que los Estados desarrollen políticas más efectivas sobre trabajo migratorio, y a su vez nutre a la sociedad civil sobre puntos prácticos en materia de defensoría. Dicho marco busca fomentar la cooperación y consulta entre las tres partes que constituyen la ort. Como un ejemplo, El Foro sobre Migrantes en Asia opera mediante una estrategia de cuatro niveles. El nivel 1 se centra en mantener la dignidad personal y el bienestar de los trabajadores migrantes, lo que significa asegurarles servicios médicos, proveerles ayuda financiera y brindarles apoyo comunitario. El nivel 2 se refiere a la prevención, divulgación y reparación de violaciones a derechos, así como a la asistencia de migrantes en riesgo. El nivel 3 trata de la capacitación, lo que significa educarlos en defensoría, construir solidaridad entre grupos y organizar la acción colectiva para la defensoría. El nivel 4 se tiene que ver con enfrentar las causas estructurales mediante una labor continua de defensoría que busca un cambio en las políticas e invirtiendo en alternativas.

Puede y debe haber mayor cohesión entre la labor orientada a servir a los trabajadores migrantes y aquélla dedicada a las políticas de defensoría. Por ejemplo, las organizaciones orientadas a dar servicio pueden registrar y categorizar sistemáticamente los casos que atienden, los cuales pueden presentarse a nivel nacional, regional e internacional como evidencia de las necesidades de protección existentes. Tal curso de acción sólo puede lograrse cabalmente mediante continuos intercambios entre grupos de asistencia a migrantes comprometidos con un esfuerzo concertado que tenga metas claras a fin de comprometer a los formuladores de políticas. Hay que crear y forta- 
lecer plataformas de intercambios, a fin de nutrir una agenda práctica que genere lazos de apoyo mutuo entre la labor de servicio y la de defensoría.

5. Las campañas para establecer acuerdos internacionales sobre derechos pueden motivar y sostener coaliciones transfronterizas de la sociedad civil y difundir los enfoques basados en derechos a sectores más amplios y diversos de la ciudadanía

Las organizaciones locales pueden estructurar la agenda de su propia política de defensoría dentro de un marco ya establecido y basado en una plataforma internacional. Al invocar los acuerdos internacionales construidos por consenso, dichas organizaciones están mejor equipadas para persuadir a sus propios gobiernos.

Si un Estado no ha ratificado la Convención Migratoria Internacional, el primer paso sería efectuar una labor de concientización sobre la necesidad de hacerlo. Una campaña a favor de la ratificar la convención constituye una oportunidad importante para formar una coalición. Una coalición propositiva y consiste promueve una imagen de credibilidad, lo que es crucial para comprometer al gobierno. Muchos sectores, además de los migrantes, tienen un interés directo en apoyar la convención, como es el caso de grupos de mujeres y sindicatos. También se puede abordar a grupos y movimientos clave a fin de constituir un movimiento más amplio r. Las coaliciones también proveen una vía para recolectar fondos; y algunos miembros pueden por ejemplo, apoyar con personal, sufragando gastos de viaje y aportando víveres.

En cada etapa del proceso, que va desde lo local y regional hasta lo nacional, se puede ir ampliando los grupos objetivo. En cada etapa hay, entre otras, organizaciones de inmigrantes o que actúan a favor de los derechos de migrantes, así como sindicatos, organizaciones religiosas, representantes académicos, organizaciones de derechos humanos, grupos de derechos civiles y organizaciones legales. A fin de facilitar la construcción de la coalición, un comité o un comité asesor puede encabezar la campaña.

Una vez construida, la coalición debe desarrollar actividades en diversas áreas para ocuparse de la defensoría o del cabildeo. Al mismo tiempo, es 
importante consolidar la coalición y sostener la campaña educando al público, consiguiendo cobertura de los medios, formando defensores, y construyendo apoyo institucional. La sociedad civil debe desempeñar una papel integral, aportando al trabajo que realizan los procedimientos especiales y mandatos especiales de la ONU, participando en misiones de recabación de evidencia en diferentes países, que investigan y documentan alegatos sobre violaciones a los derechos humanos. Asimismo, las organizaciones de la sociedad civil tienen niveles múltiples de participación en relación con las convenciones de la oIT. La sociedad civil puede reforzar su posición formando redes con otras organizaciones y sindicatos. En forma unida, y mediante la realización de consultas nacionales y regionales con los gobiernos, la sociedad civil puede abogar por un cambio en las políticas, invocando, además, las normas internacionales.

Conforme se desarrollan las campañas, habrá mucho qué aprender y compartir con otros. Una forma efectiva de atraer la atención consiste en exponer violaciones en foros internacionales. A fin de lograr que los Estados asuman su responsabilidad dentro de los marcos de referencia internacionales y también reforzar la defensoría dentro de los países, las campañas deben adoptar una visión regional y mundial en materia de creación de redes.

Las redes y organizaciones que actúan a favor de los derechos de los migrantes han utilizado diversos tipos de herramientas, tales como: peticiones urgentes, videos documentales, boletines, sitios de internet, y la producción de materiales informativos y educativos acerca de lo difícil que ha sido solicitar y forjar una solidaridad cada vez mayor con otros actores de la sociedad civil, a fin de promover una agenda basada en derechos. Al desarrollar un enfoque intersectorial, las redes de derechos de migrantes han logrado forjar una solidaridad con grupos laborales, redes comerciales, campañas por la justicia climática, así como redes feministas y de género. Varias de las campañas, aunque operan desde cierta localidad, también han desarrollado una dimensión regional e internacional, por la forma en que se han encuadrado o posicionado. La participación de migrantes en acciones como: la lucha altermundista, la acción global contra la pobreza, Jubileo Sur y Alivio de la Deuda, movilizaciones contra la Organización Mundial del Comercio, 
el movimiento sindical, las campañas para la justicia climática, y su participación en programas de comercio justo, son sólo algunos de los ejemplos de cómo los migrantes han podido trascender la dimensión local o personal de sus experiencias. Han conseguido participar en la estructuración de éstas, en un análisis que tiene que ver con experiencias en común de ser desfavorecidos explotados por una coalición de compañías transnacionales, por una clase que es una élite, y por instituciones multilaterales que originan situaciones entendidas comúnmente como los factores que tiran y jalan la migración.

Un ejemplo excelente de cómo las campañas para suscribir acuerdos internacionales basados en derechos pueden motivar y sostener coaliciones transfronterizas de la sociedad civil, difundiendo enfoques basados en derechos hacia sectores más amplios y diversos de la ciudadanía, son el recientemente finalizado (8-12 de octubre) $4^{\circ}$ Foro Social Mundial de las Migraciones, en Quito, Ecuador, ${ }^{10}$ y la $4^{\circ}$ Encuentro de Acción Global de los Pueblos sobre Migración, Desarrollo y Derechos Humanos (PGA), La AGP de la Ciudad de México es en realidad la quinta reunión. El proceso comenzó en 2006, cuando la ONU sostuvo su Diálogo de Alto Nivel sobre Migración Internacional y Desarrollo, los grupos de defensoría sostuvieron una reunión paralela sobre migración, desarrollo y derechos humanos. En 2007, el primer Foro Mundial sobre Migración y Desarrollo, de carácter oficial y que tuvo lugar en Bruselas, también estuvo acompañado por un fórum paralelo de la sociedad civil, sobre migración, desarrollo y derechos humanos. Fue en 2008, durante los preparativos que se realizaron en Filipinas, que el comité local organizador decidió llamarlo Acción Global de los Pueblos sobre Migración, Desarrollo y Derechos Humanos (para expresar el espíritu de movilización y las participaciones de la sociedad civil migrante, sindicatos, y movimientos sociales). La AGP se ha convertido en un espacio de convergencia para varias redes de migrantes y de la sociedad civil, y busca sostener la solidaridad y la acción transfronterizas, teniendo en la mira al Foro Global sobre Migración y Desarrollo, de carácter intergubernamental. Ello, con el propósito de impulsar

${ }_{10}$ Para mayor información sobre el Foro Social Mundial de las Migraciones, véase http:// www.migration4development.org/content/4th-world-social-forum-migration-2010-quito-ecuador 
una participación crítica, en términos de proceso, discurso, programa e instrumentación, y hacer valer una perspectiva sobre migración basada tanto en derechos como en la multiplicidad de intereses y voces.

\section{Las organizaciones de migrantes a menudo se conjuntan como redes,} pero sólo algunas redes pueden sostener coaliciones ${ }^{11}$

En la práctica, el término "coalición» a menudo se usa como equivalente a «redes», "campañas» $y$ "movimientos». Todos estos términos se refieren a esfuerzos para reunir a actores diferentes, con la esperanza de que el todo sea más grande que la suma de sus partes. Estos términos cotidianos, en verdad, se refieren a formas asociativas y a las relaciones que establecen, por lo cual resulta útil distinguirlas. Aunque este ejercicio de diferenciación pueda parecer "simplemente académico», una discusión más explícita acerca de los posibles diferentes significados detrás de los términos puede resultar útil, en la medida en que las formas de asociación se reafirman a sí mismas con expectativas compartidas acerca de sus metas y capacidades.

¿Qué diferencias hay entre redes, coaliciones y movimiento? Existen muchas definiciones de «red» y el estudio clásico de Keck y Sikkink ofrece una definición breve: «las redes son formas de organización que se caracterizan por patrones voluntarios, recíprocos y horizontales de comunicación e intercambio» (1998: 8). Las coaliciones, en cambio, son asociaciones entre actores distintos que coordinan la acción en busca de metas comunes (Fox, 2010). Los términos coalición y alianza son conceptualmente muy similares; ambos se refieren a actores que comparten proyectos.

En el proceso, el uso de estos términos tal cual puede generar cierta confusión. Algunas coaliciones densas se refieren a sí mismas como redes. Algunas redes delgadas se refieren a sí mismas como coaliciones. También algunas coaliciones pueden comenzar conjuntando a grupos diferentes, para después desagregarse, de lo cual puede resultar, por ejemplo, una organización diferente, que ya no está integrada por sus miembros originales pero aún así

${ }^{11}$ La discusión de esta proposición se basa en Fox (2001, 2002, 2010). 
se siguen llamando una coalición. Algunas coaliciones integradas por actores desiguales se describen a sí mismas como movimientos, exagerando de esta manera su nivel de cohesión y su identidad colectiva común. Y puede que ciertos movimientos se refieran a sí mismos como coaliciones de organizaciones. Mientras tanto, el movimiento de justicia global ha sido descrito como un «movimiento de movimientos». ${ }^{12}$

Tanto las redes como las coaliciones y movimientos se pueden participar en campañas específicas, un término que generalmente se refiere a acciones conjuntas con metas, objetivos y horizontes temporales muy precisos. Sin embargo, cuando las redes participan en una campaña de hecho, pasan del intercambio a la acción conjunta y se vuelven más como coaliciones. Una forma de establecer la distinción entre redes, coaliciones y movimientos es considerar que todos están situados a lo largo de un continuum y que cada término se refiere a un grado diferente de densidad organizativa y de cohesión social. Es más: tanto las coaliciones transnacionales como aquéllas que actúan dentro de un país enfrentan retos similares, ya que unas y otras procuran superar barreras ya sea de clase, género, raza, lengua o nacionalidad.

Sin embargo, resulta enigmático que mientras los movimientos siempre se generan a partir de redes sociales, sólo algunas redes sociales llegan a generar movimientos. La idea de movimiento también implica un alto grado de identidad colectiva en común; por contraste, ni las redes ni las coaliciones necesariamente implican un intercambio horizontal significativo entre sus participantes. De hecho, muchas redes y coaliciones transnacionales se apoyan en un puñado de interlocutores para encargarse de las relaciones entre organizaciones sociales de base amplia que pueden no estar al tanto sobre la naturaleza y las acciones de sus contrapartes. Por otra parte, algunos movimientos transnacionales pueden alcanzar un nivel muy elevado de simbolismo en común, de tal modo que sus miembros activos consiguen identificarse fuertemente entre sí, aún cuando tengan poco contacto directo, como sucedió con el emblemático caso del movimiento en contra del apartheid de los setenta y ochenta.

El concepto de movimiento social transnacional indica un grado mucho más alto de densidad y mucha mayor cohesión que el que caracteriza a las

12 Véase, por ejemplo, Sen,et al. (2004). 
redes o a las coaliciones. Para hablar de una organización con una membrecía de base organizada, que está presente en más de un país, un término más preciso sería «organización social transnacional», como es el caso del Frente Indígena de Organizaciones Binacionales (FIOB) en los EUA y México. ${ }^{13}$ Empero, muchas organizaciones de migrantes, aunque profieren una visión del mundo y una agenda transfronterizas, no necesariamente cuentan con una base social organizada en su país de origen.

El distinguir entre redes, coaliciones y movimientos también ayuda a evitar desconocer las diferencias políticas y los desequilibrios de poder, al interior de los movimientos transnacionales que desde afuera pueden parecer intrínsecamente homogéneos. Como lo señalan Keck y Sikkink, las redes transnacionales enfrentan el reto de desarrollar un «marco común de significados", a pesar de sus diferencias interculturales (1998:7). En la práctica, esos significados comunes se construyen socialmente mediante la acción común y la comprensión mutua, y no tanto por medio de valores y metas profesadas. Tampoco deben subestimarse las diferencias políticas dentro de las redes transnacionales a pesar de sus aparentes metas comunes.

A menudo las coaliciones son un medio para un fin. Aparece, entonces, una interrogante: żen qué condiciones una red se convierte en una coalición, en el sentido de la existencia de acuerdo entre sus miembros para sostener acciones conjuntas? El principio, motivado en el interés, de que «el enemigo de mi enemigo es mi amigo», puede ser suficiente para explicar la formación de coaliciones entre estados nacionales o partidos políticos, pero raramente lo es para explicar a actores de la sociedad civil. Aunque el compartir una ideología política ciertamente facilita la formación de una coalición, en sí no es un prerequisito para ello. Sin embargo a menudo cierta base de valores compartidos es clave para conjuntar a organizaciones de la sociedad civil, a pesar de muchas otras diferencias. Empero, como asunto práctico, los objetivos compartidos resultan a menudo necesarios para ir más allá de los sentimientos de solidaridad que inspiran y sostienen la acción conjunta. Los objetivos

13 Véase www.fiob.org 
compartidos ayudan a responder a la interrogante, siempre presente, de "qué corresponde hacer». Los acuerdos, organizaciones y reuniones oficiales de carácter internacional, a menudo proveen esos objetivos compartidos, sin los cuales muchas organizaciones dispares no necesariamente se unirían.

En otras palabras, los intercambios transnacionales entre organizaciones sociales pueden generar redes, las cuales pueden resultar en coaliciones, que a su vez pueden originar movimientos. Cabe destacar que al subrayar estas distinciones no se quiere dar a entender, como si fuera un juicio de valor, que mientras más cooperación transfronteriza haya, mejor. Por el contrario, las expectativas realistas respecto a qué es posible son críticas para mantener cualquier tipo de acción colectiva. Ciertamente, la cooperación transfronteriza representa costos y riesgos significativos que deben tomarse en cuenta, y también depende en alto grado de que cada lado encuentre una contraparte adecuada con quien cooperar. Estos aspectos conceptuales provienen de un proceso de intercambio regular, llamado "Diálogos», entre organizaciones sociales canadienses, estadounidenses y mexicanas, el cual ya lleva una década de existencia (1988-1998). El principio organizativo que animaba tal proceso era conjuntar contrapartes a fin de intercambiar puntos de vista acerca de las dimensiones sociales y políticas de la integración de América del Norte. El concepto de organizaciones sociales y grupos de interés público como contrapartes no necesariamente implica que deban ser similares ni estar de acuerdo, sino más bien que desempeñen papeles análogos en sus respectivas sociedades (Brooks, 1992; Brooks y Fox, 2002). Por ejemplo, en el contexto de los tres países, ello implicaba juntar en la misma mesa a sindicatos y trabajadores de las industria automovilística, telefónica y de la educación, así como a organizaciones de unidades familiares agrícolas, defensores de los derechos de migrantes, activistas en contra del abuso de sustancias tóxicas y defensores de los derechos humanos - cada uno con sus respectivas contrapartes del otro pais. En contraste con las reuniones de solidaridad, muchas de las contrapartes no necesariamente compartían ni los mismos principios ideológicos y políticos, ni la misma postura con respecto al TLCAN. Dadas la prioridades de sus bases, estos grupos ellos atendían principalemente asuntos propios en sus respectivos países y, por lo mismo 
se encontraban cara a cara con la globalización por primera vez. Por su parte, estos diálogos debidamente estructurados condujeron a situaciones de mayor entendimiento mutuo y los mismos términos del compromiso adquirido incluía la disposición a "estar de acuerdo en poder discrepar», a fin de hallar terrenos en común específicos.

\section{La construcción de coaliciones de la sociedad civil}

que buscan conjuntar a organizaciones de países tanto emisores como receptores de migrantes requiere una estrategia deliberada y una inversión continua

El activismo transnacional permite incluir muchos tipos distintos de actores $y$, por ende, propicia una perspectiva abierta y expansiva acerca de las redes de defensoría. Es aún más importante reconocer que el carácter de corto plazo de los flujos migratorios ha incidido en el fomento de lo que tradicionalmente ha sido el reclutamiento de miembros. Las uniones sindicales, por tradición, han tenido una orientación de tipo nacional, aún cuando ha habido intentos de forjar coaliciones transfronterizas. A fin de incorporar a los trabajadores migratorios en la lucha política más amplia en defensa de los derechos generales de los trabajadores y también enfrentar los agravios específicos en contra de los trabajadores migrantes o indocumentados, es preciso afianzar la colaboración entre las uniones sindicales y las organizaciones de migrantes. Estas últimas pueden beneficiarse de las estructuras organizativas de las primeras, ya que las uniones sindicales cuentan con cierta capacidad financiera e influencia política, de las cuales quizás carezcan las organizaciones de migrantes. Más allá del simple hecho de llenar espacios laborales, las organizaciones de migrantes desempeñan un papel importante en los mercados locales y nacionales. Asimismo, los trabajadores migratorios pueden revitalizar el movimiento laboral en general a favor de los sindicatos.

Entre los ejemplos de este tipo de coaliciones figura MFA, una red de organizaciones en Asia que trabaja directamente con uniones sindicales y organizaciones locales que colaboran de cerca con uniones sindicales. Y entre los 
ejemplos que operan dentro de la red del MFA (Migrant Forum in Asia, Foro sobre Migrantes en Asia), se encuentra el Centro para la Defensoría de Migrantes (Center for Migrants Advocacy, cuyas siglas son CMA), en las Filipinas, que trabaja con las uniones sindicales en materia de cabildeo. Asimismo, en Indonesia el MFA colabora con la Unión Sindical Indonesa de Trabajadores Migrantes (Indonesian Migrant Workers Trade Unión) y en Myanmar (Birmania) con la Federación de Uniones Sindicales (Federation of Trade Unions). En un esfuerzo más concertado, el MFA también ha participado en la Conferencia Internacional del Trabajo. Con su sede central en Manila, la membresía del MFA continúa creciendo en países tanto emisores como receptores, y también forma parte de una red internacional: la Internacional por los Derechos de los Migrantes (Migrant Rights International, MRI), cuya secretaría está en Ginebra, pero opera mediante un comité coordinador internacional, cuyos miembros tienen base en distintas regiones del mundo. La coordinación misma opera mediante comunicación electrónica (correo, skype y conferencias), y llevando a cabo actividades comunes en espacios que promueven un enfoque basado en la defensa y reconocimiento de derechos, como el Consejo de los Derechos Humanos de las Naciones Unidas y la misma Conferencia Internacional del Trabajo. También busca generar espacios y oportunidades para la representación. Otro miembro de la MRI es la Plataforma para la Cooperación Internacional sobre Inmigrantes Indocumentados (Platform for International Cooperation on Undocumented Migrants, PICUM), cuya secretaría se encuentra en Bruselas, y que se centra en promover el respeto por los derechos de los trabajadores indocumentados en Europa, enlazando organizaciones de base con defensores de dichas políticas a nivel continental. Tanto la PICUM como el MFA están estructurados en torno a una secretaría, un comité ejecutivo y una asamblea general. Actualmente, Picum cuenta con una red de más de un centenar de organizaciones, así como 105 miembros individuales, la cual proporciona apoyo humanitario en todo Europa. Existe también Migreurop, una asociación cuya base está en Francia y con miembros, tanto organizados como individuales, por todo Bélgica, España, Francia e Italia. Migregroup se ha ocupado de analizar diversas políticas relativas a la regulación migratoria y también ha documentado numerosos casos de violación a los 
derechos fundamentales de migrantes con respecto a detención y custodia. Su emergencia ha permitido incorporar a un amplio despliegue de investigadores, activistas y otras asociaciones.

La capacidad de esta coalición para tener éxito abogando por cambios en las políticas depende de la cohesión interna de las agrupaciones que la integran y también de saber compartir sus recursos. Una agenda realista que compromete las habilidades de la sociedad civil migrante sólo puede cumplirse maximizando los recursos y capacidades de las distintas organizaciones. La naturaleza misma del proceso migratorio obliga a que los países tanto emisores como receptores desempeñen un papel fundamental en la coalición. Más aún, la misma sociedad civil debe mantener un compromiso sostenido (permanente y continuo), a fin de que pueda llevar a cabo efectivamente campañas a corto plazo y, al mismo tiempo, dirigir los cursos de acción subsiguientes.

\section{Los migrantes organizados en distintos escenarios}

buscan la representación y la rendición de cuentas mediante distintos repertorios y múltiples canales

La interlocución política por parte de los migrantes con su país de origen puede tomar distintas formas, que va desde subordinarse políticamente al gobierno, a cambio de que éste los respalde oficialmente a la hora de una confrontación con otras autoridades del mismo país de origen, hasta cuestionar la legitimidad de un régimen que viola los derechos humanos de sus propios ciudadanos. Pero, además los términos formales en que los migrantes salen de su país varían considerablemente, lo cual también incide en el modo cómo abordan al gobierno. Así, mientras el gobierno filipino dispone un proceso altamente organizado y regulado, el cual le sirve como plataforma para una relación permanente, el de Bangladesh tiene poca credibilidad ante los migrantes, quienes, por lo mismo, tampoco buscan mantener contacto con éste. Asimismo, aunque Paquistán ha estado enviando trabajadores al Golfo Persa desde los setenta, en la sociedad civil no existe ningún paladín 
que aliente al Estado a defenderlos, de modo que pocos migrantes lo buscan en caso de dificultades. En este contexto, la postura proactiva del gobierno filipino se ve, cada vez más, como un modelo a seguir por parte de otros gobiernos asiáticos que están en busca de estrategias para «desplegar» sus trabajadores en el extranjero (en particular, Indonesia y Vietnam, así como Bangladesh, Camboya y Nepal). De manera similar, las instituciones que México ha creado para acercarse a sus migrantes son vistas como un modelo en muchos países de América Latina. ${ }^{14}$ No obstante, tanto en Filipinas como México, la creación de instituciones gubernamentales para mantener vínculos con los ciudadanos en el extranjero, fue primordialmente una respuesta a protestas y acciones de defensoría por parte de los propios migrantes, lo cual no es el caso de muchos otros países, y por ende dificulta esfuerzos de otros gobiernos para replicar la experiencia.

Las experiencias filipina y mexicana permiten plantear una pregunta más amplia: ¿̇cuándo y cómo es que los migrantes organizados se involucran en políticas de defensoría con el gobierno de su país de origen, a fin de defender los derechos de los ciudadanos que han emigrado al extranjero y/o divisar estrategias de desarrollo alternativo en el mismo país de origen? La respuesta de los gobiernos de los países de origen ha sido muy dispareja con respecto a estas dos agendas. Por un lado, los gobiernos de Filipinas y México han estado oficialmente dispuestos a aceptar cierto nivel de responsabilidad en la defensa de los connacionales que se encuentran en el exterior. Por ejemplo, la ejecución en Singapur de una trabajadora doméstica en 1995, desencadenó una ola de protesta tanto entre trabajadores migrantes en ese país como en Filipinas, y condujo a aprobar leyes de talla mayor, que obligan a las embajadas a proporcionar asistencia legal y otros servicios a los trabajadores migrantes. ${ }^{15}$ En el caso mexicano, en 1988, una ola de apoyo sin precedentes a un candidato presidencial opositor en la diáspora llevó a que el gobierno diseñara una estrategia de intervención múltiple, que incluyó el fortalecimiento de una amplia red consular para también proporcionar una amplia gama de

14 Para una visión general acerca de algunas estrategias que emplean los gobiernos para asumir compromisos con sus diásporas, véase Rannveug Agunias (2009).

15 Véase Solomon (2009), así como Rannveug Agunias y Ruiz (2007). 
servicios legales y de asistencia social, y también la creación de nuevos canales de diálogo entre la sociedad civil migrante mexicana y el Estado. ${ }^{16}$ Sin embargo, esos mismos estados nacionales no se han mostrado dispuestos para cuestionar sus modelos de desarrollo económico basados, entre otras, en la exportación de mano de obra. No es coincidencia, entonces, que hayan enmarcado su agenda de "migración y desarrollo» exclusivamente en términos de la inversión de remesas, no en cómo evitar o frenar la migración. ${ }^{17}$ Por el contrario, tanto el gobierno filipino como el mexicano han reestructurado el imaginario en que fundan su discurso oficial, en el que honran al migrante como un héroe nacional.

Además de haberse establecido un compromiso formal entre los migrantes y los Estados de sus países de origen para defender los derechos de los primeros en el extranjero, cada vez más se está reconociendo oficialmente que los migrantes puedan retener sus derechos ciudadanos ante el gobierno en su país de origen. El número de estados y territorios que han comenzado a institucionalizar el derecho al voto en alguna modalidad llegó a 115 en 2007 (IDEA/IFE, 2007:11). ${ }^{18}$ Más aún, hay 11 estados nacionales que le han otorgado representación en el poder legislativo a los ciudadanos que residen en el extranjero. ${ }^{19} \mathrm{El}$ reconocimiento del derecho al voto del migrante se está entendiendo cada vez más como parte del sufragio universal, un derecho democrático fundamental (Rhodes, Sybil y Arus Harutyyunyan, 2010). Por otra parte, estas reformas al derecho al voto frecuentemente tienen que enfrentar y superar la oposición de políticos que temen tener que responderle a un electorado que está fuera de su alcance. En sociedades fuertemente divididas, como Sri Lanka, el temor a la existencia de una diáspora políticamente empoderada ha impedido que se amplíe el derecho al voto, aún cuan-

16 Véase Ayon (2010), Fitzgerald (2004), Ishkander (2010) y González Gutiérrez (2007), entre otros.

17 Sobre la exportación de mano de obra como estrategia económica nacional, véase Rodriguez (2010), Salomon (2009), así como Delgado Wise y Marquez Covarrubias (2007).

${ }_{18}$ En los hechos el número de países es menor, si se toma en cuenta que en varios existen múltiples restricciones. Hay 14 países que, en materia de voto de ciudadanos en el exterior, sólo permiten que lo hagan funcionarios del servicio exterior.

19 Entre estos países figuran Algeria, Angola, CaboVerde, Colombia, Croacia, Ecuador, Francia, Italia, Mozambique, Panamá y Portugal (IDEA/IFE, 2007: 28) 
do en los hechos es rara la vez que el voto migrante haya resultado determinante en el resultado de una elección.

En muchos casos, y como ya se ha dicho, los gobiernos han otorgado el derecho a votar a distancia en respuesta a campañas de acción cívica, en el curso de procesos de democratización nacional. Para el migrante, que su país de origen le otorgue el derecho al voto constituye un reconocimiento simbólico de ciudadanía altamente valorado, el cual incluso puede dar lugar a que los migrantes quieran que su gobierno rinda cuentas en la defensa de una gama más amplia de derechos. Por ejemplo, los migrantes filipinos indocumentados ahora tratan más asuntos con el aparato consular, precisamente, porque se les ha reconocido como electores. Asimismo, las organizaciones de migrantes mexicanos en los Estados Unidos, habiendo sido empoderados con el voto, esperan que sus consulados los atiendan y también han formado coaliciones con estrategas dentro del gobierno que, por su parte, están interesados en relacionarse con la diáspora a fin de crear instancias de representación binacional, entre los cuales se destaca el consejo asesor del Instituto de los Mexicanos en el Exterior.

Sin embargo, en la práctica muchos regímenes también han establecido fuertes restricciones con respecto a cómo se puede ejercer el voto. Por ejemplo, Filipinas requiere que los electores en ultramar regresen al país en un plazo máximo de tres años, pues de lo contrario perderán su derecho al voto de por vida. ${ }^{20}$ En México, los partidos políticos tienen prohibido realizar campañas fuera del país y los electores residentes en el mismo país deben empadronarse dentro de México para votar, lo cual complica las cosas para aquellos que carecen del estatus legal que les permita cruzar tranquilamente la frontera. En ambos casos, si bien los electores migrantes constituyen cerca de $10 \%$ del total de la población del país respectivo, sólo han llegado a representar una porción mínima de la votación nacional en la elección presiden-

${ }^{20}$ Esto se da por sentado en los recuentos oficiales de las votaciones que se realizan en el extranjero (Philippines Committee on Overseas Absentee Voting, 2007). La experiencia migrante filipina también se distingue por sus cientos de miles de marineros contratados internacionalmente, quienes enfrentan severos obstáculos para ejercer su derecho al voto, y continúan sujetos a la repatriación forzosa de sus remesas (Prof. Steve McKay, Universidad de California, Santa Cruz, septiembre de 2010, comunicación personal). 
cial más reciente de cada país. ${ }^{21}$ Este peso democrático limitado no puede compararse con la ola de protestas callejeras en contra de la criminalización de los trabajadores indocumentados que sacudió a los Estados Unidos en 2006 y que conjuntó por lo menos a 3.5 millones de manifestantes. ${ }^{22}$

En suma, muchos migrantes se han vuelto en efecto inmigrantes, en la medida en que han luchado primordialmente por reconocimiento y derechos en los países donde se han asentado. Pero también han contribuido a la democratización de su país de origen, ya sea mediante campañas en el exterior reclamando mayor responsabilidad del gobierno, o exigiendo que éste rinda cuentas cuando están de vuelta en casa. ${ }^{23}$

\section{La participación de migrantes en proyectos de desarrollo en sus países de origen puede ser muy importante en términos de infraestructura social, pero presenta dificultades a la hora de generar empleo que evite nuevas migraciones}

Hasta ahora, la agenda sobre migración y desarrollo se ha limitado en su mayor parte a la cuestión de cómo las remesas pueden ayudar a elevar los indicadores sociales mediante transferencias entre familias. Si bien estas últimas claramente elevan los estándares así como el acceso a servicios (incluyendo educación, lo cual debería considerarse como una inversión), sólo una pequeña fracción de las remesas son colectivas y logran generar bienes públicos, inclu-

${ }^{21}$ Nótese que hay un patrón similar de una baja presencia en las urnas entre los ciudadanos dominicanos en el extranjero. (Itzigsohn y Villacrés, 2008). Generalmente, las fuentes de información oficial no ofrecen estimativos acerca de la votación neta de los migrantes en elecciones nacionales. Las fuentes más exhaustivas miden la participación electoral de los emigrantes solo en términos de cuántos se hallan registrados en el padrón electoral, y no de la fracción del numero total de emigrados eligibles que efectivamente votaron (IDEA/ IFE 2007). Aún así, la principal causa de la baja votación entre migrantes se debe a menudo a obstáculos que enfrentan para poder registrarse como electores.

22 Véase Fox yBada (2009).

${ }_{23}$ Para un análisis de la contribución democrática de las organizaciones de dominicanos y salvadoreños en diáspora, véase Itzigsohn y Villacrés (2008). Para una evaluación del impacto de la rendición de cuentas translocal por parte de asociaciones de oriundos mexicanas, véase Burgess (2010), Bada (2010), así como Fox y Bada (2008). 
so en países donde el gobierno ofrece equiparar los aportes con fondos propios. Estos proyectos de infraestructura social, por lo demás, son el eje de muchos relatos optimistas sobre proyectos oficiales en materia de migración y desarrollo. ${ }^{24}$ Sin embargo, en el caso del programa mexicano Tres por Uno, a menudo considerado como "paradigmatico», una porción muy pequeña de estos recursos se destina a la creación de empleos sustentables. ${ }^{25}$

En cuanto al reto de aumentar el impacto social de las remesas familiares, si bien es importante ofrecer servicios bancarios a quienes no suelen disponer de los mismos para que así se puedan enviar las remesas, el vínculo entre las remesas y el desarrollo, en su sentido más amplio, no es tan claro. En la práctica, los proyectos modelo innovadores siguen siendo pocos y de escala diminuta. Como resultado, aunque la agenda sobre «migración y desarrollo» ciertamente aborda el tema de la calidad de vida de los migrantes (principalmente la de las familias y de sus vecinos), todavía tiene que abordar las razones sistémicas por las que se carece de oportunidades de trabajo en las comunidades de origen.

Hay muchas razones por las cuales los proyectos de desarrollo comunitario impulsados por migrantes aún no se han centrado en inversiones productivas, de impacto y escala significativas. Consideremos la escasez de

${ }^{24}$ Para una comparación entre México y Marruecos, véase Ishkander (2007), quien contrasta el fracaso de esfuerzos concebidos 'desde arriba' para canalizar la inversión de los migrantes hacia aventurados negocios pobremente concebidos, con iniciativas más exitosas en la creación de infraestructura social, encabezadas por los propios migrantes. Véase también De Haas y Vezzoli (2010), quienes observan: «La composición fragmentaria y multilingüe de las HTA marroquíes les hace tener un poder de presión más débil en los países de recepción que el que tienen los mexicanos en Estados Unidos, a lo cual contribuye el hecho de que, en comparación con los migrantes mexicanos, los migrantes marroquíes cuentan con niveles más bajos de alfabetización y de educación. No obstante, las organizaciones marroquíes parecen estar más dirigidas al desarrollo de sus regiones de origen que sus contrapartes mexicanas».

25 Para una visión amplia del tema de las remesas y el desarrollo en México, véase García Zamora (2009), así como Fernández de Castro, García Zamora y Freyer (2009). Asimismo, para América Latina, véase García Zamora y Orozco (2009). Para 2008, después de varios años de esfuerzo, la proporción de proyectos considerados "productivos» del Programa 3 por 1 de México era sólo de 4\% (de un total de 100 proyectos), ocupando 6.4\% (2.6 millones de dólares) del presupuesto federal asignado a este Programa. Le agradecemos a Xóchitl Bada por estos datos. 
oportunidades de inversión en tantas comunidades emisoras, así como la necesidad crítica de un sentido empresarial aterrizado y de capacidades técnicas. La cuestión de la viabilidad económica tiene mucho que ver con la estructura de un proceso de toma de decisiones que se hace a la distancia. La viabilidad de un proyecto financiado con remesas depende considerablemente de una supervisión fiable, ${ }^{26}$ lo cual da lugar a una interrogante żqué papel desempeñan la ciudadanía en la comunidad de origen, así como sus autoridades públicas, que a veces han sido elegidas democráticamente? El nivel de involucramiento de cada uno de estos actores en la selección y supervisión de proyectos impulsados por migrantes varía considerablemente. $V$ a desde un extremo, en el que dicho involucramiento se ve rebasado por los mismos migrantes, muy bien organizados, hasta otro extremo, en el que los presidentes municipales viajan al exterior a fin de inducir a los migrantes a que formen asociaciones o clubes de oriundos, que a su vez soliciten fondos que apoyen su agenda de proyectos. En el bien conocido Programa Tres por Uno del gobierno mexicano, hasta hace poco la mayoría de los proyectos impulsados por las asociaciones de oriundos carecía de una contraparte en la sociedad civil, con la cual compartir la toma de decisiones y la supervisión. Y sólo recientemente se ha efectuado la promoción de un gran número de comités de proyecto locales, conocidos como «clubes espejos», con apoyo de la Secretaría de Desarrollo Social del gobierno federal. ${ }^{27}$

Más aún, hay diferencias significativas entre los proyectos de desarrollo comunitario, basados en la noción de «bienes públicos», y aquellos proyectos de desarrollo económico que implican inversiones en empresas privadas (que

26 Se requiere también de cautela política, para evitar controversias que podrían llevar a que uno de los tres niveles de gobierno involucrados ejerza su poder de veto (el Programa Tres por Uno requiere aportaciones gubernamentales federales, estatales y municipales, por lo que cada nivel de gobierno puede impedir la realización de cualquier proyecto). Las entidades federativas mexicanas que han sido lentas en transitar a la democracia también se han rezagado notablemente en incluir a ciudadanos migrantes organizados de manera independiente en el Programa Tres por Uno, como es el caso de Oaxaca.

27 Véase el informe de un taller participativo binacional que se centra especialmente en este aspecto y que, entre otras, incluye un manual oficial para promover la "fiscalización comunitaria» de los proyectos del Programa Tres-por-Uno, disponible en http://www.mexicotaller.org/Documentos.htm 
incluye cooperativas en pequeña escala). Cuando los migrantes organizados reúnen colectivamente fondos provenientes de sus ingresos, que son fruto de un trabajo arduo, para destinarlos a proyectos de desarrollo en sus pueblos de origen, le dan prelación a aquellas inversiones que pueden beneficiar a la comunidad como un todo. En cambio, la mayoría de las inversiones destinadas a generar empleo en las comunidades, sólo incide en un pequeño subconjunto de la misma (al menos en un comienzo, antes de ampliar su escala de acción). Además, se puede decir que los beneficios de tales proyectos están en riesgo de ser captados por las elites locales o por parientes bien relacionados, en un contexto en el que la rendición de cuentas a distancia es ciertamente difícil.

Hay otro aspecto de la agenda sobre migración y desarrollo que constituye un dilema potencial para migrantes organizados: que el gobierno del país anfitrión vincule los esfuerzos que realiza en materia de desarrollo a los que lleva a cabo el país emisor tratando de controlar su diáspora. Por ejemplo, en 2007 el gobierno francés creó un Ministerio de Inmigración, Integración, Identidad Nacional y Co-desarrollo (que más tarde se llamaría de «desarrollo cooperativo»), que tiene que ver con todos los proyectos de asistencia al desarrollo que involucran a migrantes. Esta dependencia tiene como tarea colocar a la migración en el centro de las políticas de desarrollo, aún cuando sólo recibe entre 1 y $2 \%$ del dinero destinado a asistencia bilateral. ${ }^{28} \mathrm{Al}$ mismo tiempo, ciertas organizaciones civiles de defensoría francesas cuestionan que el desarrollo como tal conduzca a mitigar la migración, así como el uso que el gobierno francés le da a «a la asistencia para el desarrollo como un incentivo para negociar que los países emisores controlen la emigración». ${ }^{29}$ De hecho, Francia ha usado esos modestos fondos asistenciales a fin de alentar a los países africanos para que apoyen la repatriación tanto de sus ciudadanos como los de otros países. ${ }^{30}$

${ }^{28}$ Este porcentaje es similar a la parte del presupuesto de la Secretaría de Desarrollo Social de México se destina al Programa Tres por Uno.

29 Véase Lokku y Herrgott (2009).

30 Una dinámica parecida podría emerger como parte de una eventual reforma migratoria en Estados Unidos, aunque hasta la fecha, los procesos análogos de condicionamiento no han estado vinculados con los apoyos para el desarrollo, ni con las organizaciones de migrantes. 
La persistente desconexión entre la agenda pro-derechos de migrantes y una agenda del desarrollo que vaya más allá de la infraestructura local puede relacionarse con un marco de referencia, que presupone que la agenda para el desarrollo consiste en realizar "proyectos» a partir de las remesas colectivas. Por ejemplo, en el contexto mexicano, este marco de referencia, centrado en proyectos, no se ha ampliado con una agenda alternativa de políticas públicas para el desarrollo. Incluso, aquellas entidades federativas en que han gobernado partidos políticos que se precian de estar abiertos al diálogo con los migrantes organizados aún tienen que elaborar estrategias políticas más efectivas, que conduzcan a mejoras sustanciales en materia de empleo. Se puede argumentar, en consecuencia, que se requiere introducir cambios en las políticas públicas que inciden en la creación de empleo en una escala tal, a fin de crear alternativas viables a la migración. En el caso de los países emisores de ingresos medios, el cuello de botella no necesariamente es la falta de recursos públicos, sino más el modo en que éstos se distribuyen, tal como lo da a entender el ejemplo de los subsidios agrícolas en México, que desde 1994 (año en que se inició el actual programa) han llegado a un total de 20 mil millones de dólares, pero que, por otra parte, no se han destinado principalmente a los productores campesinos. ${ }^{31}$

En materia de defensoría en temas de migración y desarrollo, hay diferencias de agenda entre quienes se centran en proyectos (trans) locales y quienes, por otra parte, se centran en políticas públicas más amplias. Puesto de manera sencilla, la primera postura puede caracterizarse como más «pragmática» y la segunda como más "política». Un enfoque centrado en proyectos encierra un par de ventajas: la posibilidad de arrojar resultados tangibles en el corto plazo y el que haya pocos riesgos de una confrontación directa con los gobiernos del país de origen. También permite que las asociaciones de oriundos se vinculen directamente con gobiernos y comunidades locales en el terruño natal. En cambio, la incidencia civil centrada en políticas de desarrollo alternativas, implica enfoques más amplios, tanto en términos de escala

Mientras que, en la pasada década, sin duda el gobierno mexicano ha reforzado el control de su frontera sur.

${ }^{31}$ Véase Fox y Haight (2010). 
como de tiempo, así como vínculos menos certeros entre posibles reformas y su impacto sobre determinados sectores de la ciudadanía en ciertos lugares.

Sin embargo, las iniciativas centradas en proyectos no necesariamente son apolíticas. Piénsese, por ejemplo, en el diseño del Programa Tres por Uno de México, una de cuyas fortalezas consiste en que se sostiene a partir de aportes de los gobiernos municipal, estatal y federal, cada uno de los cuales, por lo mismo, también tiene poder de veto. A su vez, este nivel de consenso requerido ha llevado a una elevada concentración de los proyectos en unos cuantos estados donde las organizaciones de migrantes tienen una influencia política directa en los gobiernos estatales. Al mismo tiempo, aquellas asociaciones de migrantes que realizan campañas en contra de la violación de derechos humanos en México, o que están a favor de políticas de desarrollo alternativas más amplias (sin mencionar el que se asocien con partidos políticos de oposición), bien pueden verse excluidas del Programa Tres por Uno. En este contexto, el hecho de priorizar proyectos locales a corto plazo también es claramente una decisión política. ${ }^{32}$

Para las estrategias de incidencia de migrantes que se interesa más en políticas de desarrollo alternativas, el contexto político puede cambiar si es que en el país de origen llega al poder un gobierno del cual forman parte fuerzas que están dispuestas a cuestionar la estrategia de exportación de fuerza de trabajo y, en cambio, priorizan la creación de puestos de trabajo, como ha ocurrido recientemente en El Salvador. En dicho contexto, los migrantes organizados tienen la posibilidad de avanzar simultáneamente por ambas vías: realizando proyectos translocales y también contribuyendo a cambiar las políticas de desarrollo a nivel nacional. En términos más generales, para construir agendas de desarrollo alternativo resulta indispensable construir

32 Ayon argumenta que la estrategia multifacética del gobierno mexicano en el involucramiento con su diáspora, ha tenido éxito en despolitizar la relación entre ambos: «Las autoridades mexicanas han rebasado y finalmente dejado atrás lado a los activistas migrantes de ideología opositora usando el poder del Estado para acercarse a la diáspora organizada, e incluso darle un nuevo rostro. Al paso de tres administraciones [presidenciales] y de un cambio fundamental en el régimen, el interés subyacente del Estado mexicano de alejar el activismo migrante trasnacional de la política nacional ha prevalecido ...» (Ayon 2010: 245). Véase también Délano (2009), Ishkander (2010) y Smith (2009). 
coaliciones efectivas, con actores políticos y de la sociedad civil comprometidos con la creación de empleo a gran escala en el país de origen.

10. La dinámica de una coalición cuyo compromiso consiste en realizar campañas a favor de los derechos de los migrantes es muy diferente a la de una coalición cuyo compromiso consiste en abordar cuestiones de desarrollo y las causas estructurales de la migración

Persistente una desconexión entre las campañas que abogan por los derechos de los migrantes en el país receptor y las campañas centradas en políticas de desarrollo alternativo y que se realizan en el país emisor. Cada agenda puede o no encajar bien con la otra. Por lo mismo, hay que fijarse en cómo se estructuran los intereses involucrados en cada una. La agenda de los migrantes actuales puede que se traslape sólo en algunos puntos con la de los migrantes potenciales (o a futuro), quienes quizás estén mucho más interesados en alentar a su propio gobierno para que divise estrategias consistentes en materia de creación de empleo.

Ahora piénsese en el caso del debate acerca del futuro de los trabajadores «no autorizados» en los Estados Unidos. La actual correlación de fuerzas políticas en el país sugiere que cualquier escenario para una reforma migratoria comprensiva en el futuro cercano conllevará una suerte de »toma y dame» en lo relativo al trato que recibirán los actuales y los eventuales migrantes. Más específicamente, una porción de los actuales migrantes quizás consiga regularizar su estatus legal, pero en el contexto de un endurecimiento del control en la frontera y medidas más severas para aquellos migrantes que no puedan acceder a un proceso de regularización que puede terminar siendo muy arduo, punitivo y excluyente. Si esta predicción se cumpliera, dicho contexto político e institucional podría generar tensión dentro de la sociedad civil migrante, entre los actuales y los futuros migrantes. Si se llega a presentar una oportunidad para una regularización, lo más probable es que se limite a (algunos) migrantes actuales. El endurecimiento del control fron- 
terizo afectará, evidentemente, a los que la crucen en el futuro. Por otra parte, aunque la regularización del estatus es el asunto más apremiante para los actuales migrantes, es la agenda relativa al desarrollo nacional la que afectará más directamente a los posibles futuros migrantes. Esta diferencia en la estructura de intereses plantea un dilema a la hora de construir y sostener agendas transfronterizas comunes en materia de migración y desarrollo.

Ahora bien, desde el punto de vista del país emisor, y en un esfuerzo por configurar un nuevo modo de concebir la relación entre migración y desarro1lo, Armando Bartra, un estratego mexicano en el campo del desarrollo rural, propone un puente diferente entre las agendas relativas a migración, desarrollo y derechos, al efectuar un llamado para respetar el derecho a no (tener que) migrar (2003, Global Exchange 2008). Después de todo, la Constitución mexicana sí establece el derecho de la ciudadanía a un trabajo digno y socialmente útil. Así «el derecho a no migrar» puede ser un concepto puente útil para promover la reflexión y la discusión entre actores no sólo distintos, sino disímiles, que, por lo mismo, ven a la migración en forma diferente. En tanto principio, este derecho reconoce que si bien la migración constituye una opción, es una decisión que se toma dentro de un contexto impuesto por políticas públicas que privilegian ciertas estrategias de desarrollo en detrimento de otras.

Uno de los enfoques más importantes en lo relativo a conectar las agendas sobre migración, desarrollo y derechos, es la creciente consolidación de coaliciones transfronterizas que conjuntan a migrantes procedentes de distintos países. El Foro Migrante en Asia (MFA) incluye a organizaciones con sedes en países tanto emisores como receptores del continente, y organiza su labor en torno a grupos de trabajo que se comprometen a trabajar sobre asuntos relacionados con la feminización de la migración laboral, capacitación y defensoría, la colaboración asociada con organizaciones en el occidente de Asia, el derecho de atención a la salud, y en programas de construcción de coaliciones (tales como entre uniones sindicales y ONG), así como campañas que se centran en los derechos de los trabajadores migrantes y trabajadoras domésticas migrantes, y la ratificación universal de la Convención 
Internacional sobre la Protección de los Derechos de Todos los Trabajadores Migratorios y de sus Familiares. ${ }^{33}$

En los Estados Unidos, la Red Nacional para los Derechos de los Inmigrantes y los Refugiados (National Network for Immigrant and Refugee Rights, NNIRR) establecida en 1986, conjunta a organizaciones de base, y también comunitarias, religiosas, sindicales, legales y de derechos humanos, para ayudar a construir un movimiento social en apoyo a inmigrantes y refugiados. ${ }^{34}$ Dicha red ha organizado campañas y conferencias regionales y nacionales, ha apoyado el desarrollo de un liderazgo migrante diversificado, incluyendo el desarrollo de recursos para la capacitación y de oportunidades para ello. También ha encabezado manifestaciones y marchas y ha iniciado redes de comunicación, elaborando boletines, informes y materiales educativos, habiéndose así forjado una reputación de tener posturas progresistas claras y articuladas, y generar análisis con estas mismas características. Entre sus objetivos estratégicos figuran conectar e integrar a las comunidades de inmigrantes, así como al movimiento en favor de los derechos de los inmigrantes, con movimientos globales que actúan a favor de la justicia social y económica, y también fortalecer tanto la visión como el liderazgo del movimiento a favor de los derechos de los inmigrantes desde la perspectiva de los derechos humanos.

La Alianza Nacional de Comunidades Latinoamericanas y Caribeñas (NALACC) que conjunta a organizaciones comunitarias de migrantes de diversas nacionalidades en los Estados Unidos, trabaja para mejorar la calidad de vida en sus respectivas comunidades, tanto en Estados Unidos como en los países de origen ${ }^{35}$ La NALACC busca construir liderazgos transnacionales y ha centrado buena parte de su labor en intentar reformar las políticas de inmigración estadounidenses relacionadas con las causas profundas de la migración, así como en los retos que enfrentan los migrantes en el país. En materia de incidencia transfronteriza, la NALACC tiene un claro interés en las políticas públicas existentes en los países de origen, cosa que la distingue de otras organizaciones de migrantes. Mientras que el hecho de que la NALACC

\footnotetext{
${ }^{33}$ http://www.mfasia.org/

34 Véase http://nnirr.org/

35 Véase http://nalacc.org/ 
esté encabezada por migrantes la distingue de otras organizaciones latinas en los Estados Unidos, que suelen estar estrechamente vinculadas con funcionarios electos.

Recientemente en Mali, se constituyó la Red Panafricana en Defensa de los Derechos de los Migrantes, producto de discusiones iniciales en torno a una perspectiva y crítica africana hacia el discurso predominante en materia de migración y desarrollo. Esta red tuvo su origen en la participación de grupos que trabajan desde África y de aquellos que representan a la diáspora africana durante la reunión de la Acción Global de los Pueblos sobre Migración, Desarrollo y Derechos Humanos, que tuvo lugar en Manila en 2008. En el curso de su asamblea inaugural, la Red Panafricana decidió consolidar su membresía y que trabajar de manera colaborativa construyendo las capacidades de las organizaciones que la integran. Ello con el fin elevar la presencia y el papel de los asuntos africanos en el avance de los derechos fundamentales de los trabajadores migratorios en general, reflexionando a partir de sus propios retos, perspectivas y posturas críticas, a fin de crear un marco de referencia desde donde también puedan verse los programas sobre migración y desarrollo.

Estos encuentros, como la reunión de Acción Global de los Pueblos sobre Migración, Desarrollo y Derechos Humanos y el Foro Social Mundial sobre Migración y demás procesos y movilizaciones de la sociedad civil global, han permitido contar con espacios comunes en que las organizaciones de migrantes y las comunidades de inmigrantes han podido no sólo intercambiar ideas y fertilizarse mutuamente, sino también forjar solidaridades, generando así «ámbitos de acción colectiva», en que cada arena está constituida por actores y cada conjunto de actores constituye una arena.

\section{CONCLUSIONES}

De estas diez propuestas para la discusión emanan las siguientes recomendaciones:

1) Es importante que se reconozca genuinamente el papel que cumple la sociedad civil migrante en una agenda migratoria centrada en formular polí- 
ticas (así como en los respectivos programas), y en que prevalezca un discurso multidimensional, dado que intervienen múltiples actores e intereses. A este respecto, el proceso del Foro Mundial sobre Migración y Desarrollo (GFMD, por sus siglas en inglés), actualmente en su cuarto año, todavía tiene que dar con un modelo efectivo que tome en consideración los planteamientos emanados de las deliberaciones de la sociedad civil. Las Jornadas de la Sociedad Civil que se programaron en la reunión del GFMD, realizada en Puerto Vallarta (México), junto con la reunión de la Acción Global de los Pueblos sobre Migración, Desarrollo y Derechos Humanos, constituyen definitivamente una gran mejora en términos de proceso; sin embargo, su efectividad todavía no ha sido puesta a prueba. El reto sería desarrollar mecanismos que estén activos entre una reunión del GFMD y otra, a fin de propiciar una participación sostenida de la sociedad civil en el nivel multilateral.

2) Tanto en el país emisor como en el receptor, la sociedad civil debe reconocer que la experiencia de los migrantes va más allá de las violación a los derechos humanos y laborales individuales e incluso colectivos y, en consecuencia, comprometerse con los migrantes en acrecentar su comprensión de las presiones migratorias que han sido desencadenadas por el paradigma de desarrollo económico global neoliberal. La construcción de una alianza intersectorial, en tanto enfoque, es crucial para desarrollar análisis más profundos y críticas al fenómeno de la migración hoy en día, así como para construir una solidaridad entre los pueblos de cara al abuso y a la explotación.

3) Se debe movilizar recursos para apoyar a organizaciones encabezadas por migrantes, así como a instituciones, redes y plataformas, a fin de que se puedan gestar programas de capacitación, que a su vez le den voz a los migrantes y a sus perspectivas acerca de cómo pueden volverse miembros más plenos de la sociedad. Tanto el Foro Social Mundial de las Migraciónes (FSMM) como la Acción Global de los Pueblos sobre Migración, Desarrollo y Derechos Humanos (AGP), han sido procesos, en buena parte, iniciados e impulsados por la sociedad civil migrante, con recursos sumamente limitados, y a costas de un gran esfuerzo desplegado en la movilización de la sociedad civil migrante mundial. Vale la pena buscar mayor apoyo institucional para el próximo FSMM, a realizarse en Corea del Sur en 2012 y para el siguiente AGP, que se llevará a cabo en 2011. 
4) Las autoridades de los Estados deben reconocer a las alianzas, coaliciones, redes y movimientos transfronterizos y transnacionales, sean actuales o emergentes. Ello, de manera inclusiva, de tal modo que no se vean obligadas a fundirse en una identidad ni una sola voz. Es preciso apreciar la pluralidad y la diversidad de la sociedad civil migrante, a fin de que se de lugar a una comprensión más profunda de la complejidad del ciclo migratorio.

5) La sociedad civil migrante debe estar más atenta y vigilante ante discursos que generan descontento y fragmentación a su interior, como las perspectiva en que se habla de "país emisor y país receptor», "trabajador migrante versus inmigrante», «inmigrante versus diáspora», "documentados versus indocumentados», "migrante económico versus refugiado», "dirigencia migrante versus a poyo a migrantes», "migrante versus traficante versus contrabandista", etc. Estas caracterizaciones, aún cuando son importantes en la medida en que ayudan en la realización de campañas a favor de ciertas políticas y programas con los que se pretende enfrentar determinadas vulnerabilidades y formas de explotación, también son limitadas. Esto, por cuanto hacen que los individuos y programas que se insertan en dichas categorías se vuelvan miopes e incluso competitivos en un sentido destructivo, ya sea actuando en forma vengativa o acercándose a programas sólo para aliviar asuntos de su propia causa. Se requiere invertir mucho esfuerzo deliberado y concertado en forjar una agenda común, fundada en análisis críticos que estén ligados a un marco de reflexión común y compartido, relativo a los asuntos y que explique las distintas circunstancias que están emergiendo.

6) También hay que realizar una labor consistente y continua dentro de la sociedad civil migrante a fin de sensibilizar a los medios con respecto a los asuntos y preocupaciones de los trabajadores migrantes, y también para contrarrestar las percepciones negativas de los medios, y que alimentan el odio y la discriminación en contra de los migrantes. Dicha labor también debe proponerse recabar mayor apoyo entre el público hacia el reconocimiento de los migrantes como agentes de cambio social y de desarrollo, tanto en los países de origen como en los de destino.

Las libertades de asociación y de negociación colectiva son derechos laborales fundamentales, tal como las define la Organización Internacional 
del Trabajo, lo cual también ha sido reconocido recientemente por el Consejo de los Derechos Humanos de las Naciones Unidas, al adoptar una resolución, que no requirió ser votada, por la cual creó un mandato de Procedimiento Especiales denominado Relatoría Especial sobre la promoción y protección del derecho a la libertad de opinión y de expresión (A/HRC/15/ L/23). Sucede que en muchos países anfitriones, a los migrantes se les niega este derecho, y en otros donde ni siquiera existe, los trabajadores frecuentemente dudan en ejercerlo por temor a perder su trabajo. Resulta imperativo, entonces, no negarles estos derechos fundamentales a los migrantes, para que tengan la libertad de reunirse y formar sus propias asociaciones y uniones sindicales, siguiendo líneas de afinidad o experiencias compartidas, a fin de que puedan abordar sus asuntos de la mejor manera.

7) Con el fin de integrar y desarrollar una sociedad multicultural, los migrantes y sus comunidades deben poder disfrutar de sus derechos sociales en condiciones de igualdad con respecto a la población nacional del país anfitrión, y en apego estricto al principio fundamental de la no-discriminación, que enmarca a toda norma internacional en materia de derechos humanos. Por estas mismas razones, los migrantes deben poder ejercer sus derechos civiles y políticos en su país de origen (incluyendo el sufragio) y también en el de destino, ya sean residentes temporales o permanentes. El reconocimiento de los derechos sociales y políticos de los migrantes es un asunto clave para su empoderamiento y el de sus comunidades. Por lo mismo, va mucho más allá de la habitual visión estatal de la migración, que suele entenderla como un proceso generador de remesas. Dicho reconocimiento constituye un llamado para forjar una base genuina y responsable (en el sentido de la rendición de cuentas) entre migración y desarrollo.

8) Los migrantes que tienen un estatus irregular o de indocumentado, no deben ser vistos ni tratados como una amenaza a la seguridad nacional, ni ser objeto de arrestos arbitrarios, detenciones ni deportaciones. Más bien, la situación de migrantes indocumentados e irregulares debe enmarcarse en el discurso de la seguridad humana y como una "situación creada» por la dinámica de una economía de mercado global que opera a destajo, en que los migrantes indocumentados e irregulares son un "factor necesario» en una 
carrera hacia el fondo del barril en términos de bajos salarios, a fin de poder ser competitivos en el mercado mundial.

9) A fin de evitar que se socaven los tratados internacionales sobre derechos humanos y que se polarice la relación entre los países desarrollados y los países en desarrollo, es imperativo que los estados miembros de las Naciones Unidas adopten, ratifiquen y monitoreen efectivamente la instrumentación de la Convención Internacional sobre la Protección de los Derechos de Todos los Trabajadores Migratorios y de sus Familiares de la onu de 1990, así como otros convenios, recomendaciones y marcos de referencia de la oIT ONU sobre el tema.

10) Hay que desplazarse más allá de que "migración y desarrollo» se refiere solamente a flujos migratorios actuales, como si no hubiera una correlación entre ambos procesos. La agencia de los migrantes y de la sociedad civil migrante todavía tiene encontrar un espacio auténtico de transparencia y rendición de cuentas en la agenda del desarrollo tanto de los países de origen como los de destino. El Foro Mundial sobre Migración y Desarrollo tiene que avanzar hacia una visión más amplia y compleja de los vínculos entre migración y desarrollo, yendo más allá de unos cuantos pequeños proyectos para involucrarse en las políticas de desarrollo nacional e internacional, en que la sociedad civil migrante participe plenamente en el diseño, monitoreo e implementación de las mismas. Es tiempo de que los estados miembros de la ONU dejen atrás la polémica y la politización para, más bien, entrar a aplicar la resolución vigente de la Asamblea General de la onu que hace un llamado a realizar una Conferencia Mundial sobre Migración y Desarrollo.

\section{BIBLIOGRAFÍA}

ANDERSON, Bridget (2001), «Different Roots in Common Ground: Transnationalism and Migrant Domestic Workers in London», Ethnic and Migration Studies, 27(4), octubre.

(2010), «Mobilizing Migrants, Making Citizens: Migrant Domestic Workers as Political Agents", Ethnic and Racial Studies, 33(1), enero. 
Ayon, David (2010), "Taming the Diaspora: Migrants and the State, 1986-2006», en Andrew Selee y Jacqueline Peschard (comps.), Mexico's Democratic Challenges: Politics, Government and Society, Washington y Palo Alto, Woodrow Wilson Center Press/Stanford University Press.

BaCon, David (2008), Illegal People: How Globalization Creates Migration and Criminalizes Immigrants, Nueva York, Beacon.

BADA, Xóchitl (2010), "Mexican Hometown Associations as Accountability Agents: Opportunities and Challenges in Participatory Planning for Community Development in Michoacán», ponencia ante la Asociación de Estudios Latinoamericanos (LASA), Toronto, octubre.

BADA, Xóchitl, Robert Donnelly, Jonathan Fox y Andrew Selee (2010), La importancia del contexto: El compromiso cívico de los inmigrantes latinos en nueve ciudades de los Estados Unidos, Washington, D.C., Centro Internacional Woodrow Wilson para Académicos, Instituto México, abril de 2010, www.wilsoncenter.org/migrantparticipation

BARTRA, Armando (2008), Cosechas de ira: Economía politica de la contrarreforma agraria, México, Editorial Ítaca/Instituto Maya.

Briones, Leah (2009), "Reconsidering the Migration-Development Link: Capability and Livelihood in Filipina Experiences of Domestic Work in Paris», Population, Space and Place, 15.

Brooks, David (1992), "The Search for Counterparts», Labor Research Review, Núm. 19 , otoño.

Brooks, David y Jonathan Fox comps. (2002), Cross-Border-Dialogues: US-Mexico Social Movement Networking, La Jolla: Universidad de California en San Diego, Centro de Estudios México-Estados Unidos.

Burgess, Katrina (2010), "Translocal Networks and Democratic Accountability in Mexico", ponencia ante la Asociación de Estudios Latinoamericanos (LASA), Toronto, octubre.

Daily, Star (2008), «Bangladesh Workers Agitate Over Poor Pay, 15 Hurt, 60 Arrested in Kuwaiti Police Action", 30 de julio de 2008.

HaAs, Hein de y Simona Vezzoli (2010), "Time to Temper the Faith: Comparing the Migration and Development Experiences of Mexico and Morocco», Migration Information Source, julio de 2010, http://www.migrationinformation.org/Feature/display.cfm? $\mathrm{ID}=791$

Délano, Alexandra (2009), «From Limited to Active Engagement: Mexico's Emigration Policies from a Foreign Policy Perspective (2000-2006)", International Migration Review, 43(4), invierno. 
Delgado Wise, Raul y Humberto Márquez Covarrubias (2007), «The Reshaping of Mexican Labor Exports under NAFTA: Paradoxes and Challenges», International Migration, 41(3), septiembre.

Dumont, Antoine (2008), «Representing Voiceless Migrants: Moroccan Political Transnationalism and Moroccan Migrants' Organizations in France», Ethnic and Racial Studies, 31(4).

Fernández de Castro, Rafael, Rodolfo García Zamora y Ana Vila Freyer (comps.) (2007), El Programa 3x1 para migrantes: iPrimera política transnacional en México?, México: Ed. Miguel Ángel Porrúa/Instituto Tecnológico Autónomo de México/ Universidad Autónoma de Zacatecas

FIne, Janice (2006), Worker Centers: Organizing Communities at the Edge of the Dream, Ithaca, Cornell.

Fitzgerald, David (2004), "For 118 Million Mexicans»: Emigrants and Chicanos in Mexican Politics», en Kevin Middlebrook (comp.), Dilemmas of Political Change in Mexico, Londres, Instituto de Estudios Latinoamericanos (ILAS).

Fox, Jonathan (2001), "Evaluación de las coaliciones binacionales de la sociedad civil a partir de la experiencia México-Estados Unidos», Revista Mexicana de Sociologia, 63(3), http://escholarship.org/uc/item/3d95f9sm

(2002), «Lessons from Mexico-US Civil Society Coalitions», en David Brooks y Jonathan Fox (comps.), Cross-Border Dialogues: US-Mexico Social Movement Networking, La Jolla, Universidad de California, San Diego, Centro de Estudios México-Estados Unidos.

(2006), «Repensar lo rural ante la globalización: La sociedad civil migrante», Migración y Desarrollo, Núm. 5, http://escholarship.org/uc/item/6f2225fp (2007),Accountability Politics: Power and Voice in Rural Mexico, Oxford University Press.

(2010) «Coalitions and Networks», en Helmut Anheier y Stefan Toepler (comps.), International Encyclopedia of Civil Society, New York, Springer Publications, http://escholarship.org/uc/item/1x05031j

Fox, Jonathan y Xóchitl Bada (2008), "Migrant Organization and Hometown Impacts in Rural Mexico", Journal of Agrarian Change, 8 (2-3), http://escholarship. org/uc/item/7jc3t42v

(2010), "Migrant Civic Engagement», en Irene Bloemraad y Kim Voss (comps.), Rallying for Immigrant Rights, Berkeley: University of California Press, [También fue publicado en Research Paper Series on Latino Immigrant Civic 
and Political Participation, Núm. 3, junio de 2009, www.wilsoncenter.org/migrantparticipation]

Fox, Jonathan y Libby Haight (comps.) (2010), Subsidios para la desigualdad: Las políticas públicas del maíz en México a partir del libre comercio, México: Centro Wilson/Cide/ Universidad de California en Santa Cruz, www.wilsoncenter.org/ DesarrolloRuralMexicano

García Zamora, Rodolfo (2009), Desarrollo económico y migración internacional: los desafíos de las políticas públicas en México, Zacatecas: Universidad Autónoma de Zacatecas.

García Zamora, Rodolfo y Manuel Orozco (comps.) (2009) Migración internacional, remesas y desarrollo local en América Latina y el Caribe, México, Ed. Miguel Ángel Porrúa/Universidad Autónoma de Zacatecas/Inter-American Dialogue.

Gleeson, Shannon (2010), «Labor Rights for All? The Role of Undocumented Immigrant Status for Worker Claims-Making», Law \& Social Inquiry, 35(3).

Global ExChange (comp.) (2008), The Right to Stay Home: Alternatives to Mass Displacement and Forced Migration in North America, San Francisco: Global Exchange, http://www.globalexchange.org/countries/americas/mexico/TheRighttoStayHome.html

Gors, William (2009), «IOM Dialogue on Migration: Effective Respect for the Human Rights of Migrants-A Shared Responsibility», ponencia ante la Organización Internacional para las Migraciones (OIM), Ginebra, 25 y 26 de marzo.

(2010), «Exploring Migration and Development Linkages and Reclaiming What is Human and Rights in the Discourse», Migrant Forum in Asia 2009. [También fue publicado en Refugee Survey Quarterly 28 (4), http://rsq.oxfordjournals.org/content/28/4/201.full]

González Gutiérrez, Carlos (2009), «The Institute of Mexicans Abroad: An Effort to Empower the Diaspora», en Dovelyn Rannveug Agunias (comp.), Closing the Distance: How Governments Strengthen Ties with Their Diasporas, Washington, D.C., Instituto de Política Migratoria (MPI).

IDEA/IFE (2007), Voting from Abroad: The International IDEA Handbook, Estocolmo/ Ciudad de México: Instituto Internacional para la Democracia y la Asistencia Electoral (IDEA)/ Instituto Federal Electoral, http://www.idea.int/vt/

IsHKander, Natasha (2010), Creative State: Forty Years of Migration and Development Policy in Morocco and Mexico, Ithaca, Universidad de Cornell.

Itzigsohn, José y Daniela Villacrés (2008), «Migrant Political Transnationalism and the Practice of Democracy: Dominican External Voting Rights and Salvadoran Home Town Associations», Ethnic and Racial Studies, 31(4). 
Keck, Margaret y Kathryn Sikkink (1998), Activists Beyond Borders, Ithaca, Cornell. Kessler, Christl (2009), «Democratic Citizenship and Labour Migration in East Asia: Mapping Fields of Enquiry», European Journal of East Asian Studies, 8(2).

LoKku, Sonia y Katia Herrgott (2009), «Incoherence between Migration and Development Policies: The Case of France», European Social Watch Report 2009: Between Hope and Vulnerability, Bruselas, Eurostep, www.socialwatch.eu

Martínez Saldaña, Jesús y Raúl Ross Pineda (2002), «Suffrage for Mexicans Residing Abroad», en David Brooks y Jonathan Fox (comps.), Cross-Border Dialogues: USMexico Social Movement Networking, La Jolla, Universidad de California en San Diego, Centro de Estudios México-Estados Unidos.

Migrant Forum IN AsIA, "Models of Transnational Organizing: MFA's Experience in Asia», Manila, s.f.

MiLkman, Ruth (2006), LA Story, Immigrant Workers and the Future of the US Labor Movement, Nueva York, Russell Sage.

MoYA, José (2005), «Immigrants and Associations: A Global and Historical Perspective», Journal of Ethnic Migration Studies, 31(5).

Navarro Fierro, Carlos y Manuel Carrillo (2007), "Mexico: Safeguarding the Integrity of the Electoral Process», Voting from Abroad: The International IDEA Handbook, Estocolmo/Ciudad de México, Instituto Internacional para la Democracia y la Asistencia Electoral (IDEA)/ Instituto Federal Electoral, http://www.idea.int/vt/ Pangsapa, Piya (2009), «When Battlefields become Marketplaces: Migrant Workers and the Role of Civil Society and NGO Activism in Thailand», International Migration.

Philippines Committee on Overseas Absentee Voting (2007), «The Philippines: The First Experience of Overseas Absentee Voting», Voting from Abroad: The International IDEA Handbook, Estocolmo/Ciudad de México, Instituto Internacional para la Democracia y la Asistencia Electoral (IDEA)/ Instituto Federal Electoral, http://www.idea.int/vt/

Rannveug Agunias, Dovelyn (comp.)(2009), Closing the Distance: How Governments Strengthen Ties with Their Diasporas, Washington, D.C., Instituto de Política Migratoria (MPI).

Rannveug Agunias, Dovelyn y Niel G. Ruiz (2007), «Protecting Overseas Workers: Lessons and Cautions from the Philippines», Washington, D.C Instituto de Política Migratoria (MPI) septiembre, http://www.migrationpolicy.org/research/ migration_development.php 
Rhodes, Sybil y Arus Harutyyunyan (2010), «Extending Citizenship to Emigrants: Democratic Contestation and a New Global Norm», International Political Science Review, 31(4).

Rodriguez, Robyn Magalit (2010), Migrants for Export: How the Philippine State Brokers Labor to the World, Mineápolis, Universidad de Minesota.

RoJAs, Henry (2007), Overseas Absentee Voting: The Philippine Experience, Manila, http://www.pinoy-abroad.net/lungga/index.shtml?apc $=\mathrm{i}-\mathrm{-6181-}$ (2010) «Post 2010 oAv Reflections», Manila 12 de mayo,

http://www.pinoy-abroad.net/lungga/index.shtml?apc $=$ n--8961Post $+2010+0$ $\mathrm{AV}+$ Reflections

Rother, Stefan (2009), "Changed in Migration? Philippine Return Migrants and (Un)Democratic Remittances», European Journal of East Asian Studies, 8(2).

Rüland, Jürgen, Christl Kessler y Stefan Rother (2009), "Democratization Through International Migration? Explorative Thoughts on a Novel Research Agenda», European Journal of East Asian Studies, 8(2).

Sen, Jai, Anita Anand, Arturo Escobar, y Peter Waterman comps. (2004), World Social Forum: Challenging Empires, Nueva Delhi: Fundación Viveka.

SMITH, Robert Courtney (2008), "Contradictions of Diasporic Institutionalization in Mexican Politics: The 2006 Migrant Vote and Other Forms of Inclusion and Control», Ethnic and Racial Studies, 31(4), mayo.

Solomon, M. Scott C., "State-led Migration, Democratic Legitimacy, and Deterritorialization: The Philippines' Labour Export Model», European Journal of East Asian Studies, 8(2).

Stephen, Lynn (2007), Transborder Lives: Indigenous Oaxacans in Mexico, California, and Oregon, Duke University Press.

Teo, Youyenn y Nicola Piper (2009), «Foreigners in Our Homes: Linking Migration and Family Policies in Singapore», Population, Place and Space, 15.

VARSAnYI, Monica (2007), «Documenting Undocumented Migrants: The Matrículas Consulares as Neoliberal Local Membership», Geopolitics, 12(2), abril.

Waldinger, Roger (2009), "A Limited Engagement: Mexico and its Diaspora», Universidad de California, Los Ángeles, Departamento de Sociología. 